\title{
Effects of dietary fats differing in $n-6: n-3$ ratio fed to high-yielding dairy cows on fatty acid composition of ovarian compartments, follicular status, and oocyte quality
}

\author{
M. Zachut, ${ }^{*}$ I. Dekel, ${ }^{*}$ H. Lehrer, ${ }^{*}$ A. Arieli,† A. Arav, ${ }^{*}$ L. Livshitz, ${ }^{*}$ S. Yakoby, ${ }^{*}$ and U. Moallem*1 \\ *Department of Dairy Cattle, Institute of Animal Sciences, Volcani Center, PO Box 6, Bet-Dagan, 50250 Israel \\ †Department of Animal Science, Faculty of Agricultural, Food and Environmental Sciences, Hebrew University of Jerusalem, Rehovot, 76-100, \\ Israel
}

\begin{abstract}
The objectives were to determine the incorporation of dietary encapsulated fats differing in n-6:n-3 ratio into milk fat, plasma, and various ovarian compartments and to examine the effects on ovarian follicular status, preovulatory follicle characteristics, and oocyte quality. Twenty-four multiparous Israeli Holstein cows, averaging $114 \mathrm{~d}$ in milk, were assigned to 1 of 3 treatment groups: 1) control $(\mathrm{n}=7)$, in which cows were fed a lactating cow diet; 2$)$ E-FLAX $(\mathrm{n}=8)$, in which cows were fed a lactating cow diet that consisted of $1 \mathrm{~kg} / \mathrm{d}$ of encapsulated fat (3.8\% of dry matter) containing $40.8 \%$ flaxseed oil, providing $242.2 \mathrm{~g}$ of C18:3n-3 (low n-6:n-3 ratio); or 3$)$ E-SUN $(\mathrm{n}=9)$, in which cows were fed a lactating cow diet that consisted of $1 \mathrm{~kg} / \mathrm{d}$ of encapsulated fat $(3.8 \%$ of dry matter) containing $40.8 \%$ sunflower oil, providing $260.0 \mathrm{~g}$ of C18:2n-6 (high n-6:n-3 ratio). Ovaries were monitored by ultrasonography for follicular status, and after synchronization, follicles $>7$ $\mathrm{mm}$ were aspirated and evaluated. Ovum pickup was performed (19 sessions for the control and E-FLAX groups and 11 for the E-SUN group), and in vitro maturation and oocyte fertilization were conducted. The E-FLAX treatment increased the proportions of C18:3n-3 (5.8 fold), C20:5n-3, and C22:5n-3 (approximately 4 -fold) in milk fat as compared with the other 2 treatments. The proportion of C18:3n-3 fatty acid in plasma increased dramatically with the E-FLAX treatment, from 1.43 and $1.49 \%$ in the control and E-SUN groups, respectively, to $7.98 \%$ in the E-FLAX group. Consequently, the n-6:n-3 ratio in plasma was reduced from approximately 42 in the control and E-SUN groups to 6.74 in the E-FLAX group. Proportions of C18:3n-3 in follicular fluid and granulosa cells were approximately 5 -fold higher in the E-FLAX group than in the other 2 groups. The percentage of C18:2n-6 in cumulus-
\end{abstract}

Received February 26, 2009.

Accepted November 7, 2009.

${ }^{1}$ Corresponding author: uzim@volcani.agri.gov.il oocyte complexes of cows in the E-SUN group was $54 \%$ higher than that in the E-FLAX group and was 2.4-fold higher than that in the control group; the proportion of C18:3n-3 in the E-FLAX group was $4.73 \%$ and was not detected in the other groups. The average numbers of 2- to 5 - $\mathrm{mm}$ follicles on d 5 and 9 of the cycle were higher in the E-FLAX group than in the E-SUN group, whereas the average numbers of follicles $\geq 10 \mathrm{~mm}$ on $\mathrm{d}$ 5,9 , and 13 were higher in the E-SUN group than in the other 2 groups. The estrous cycles of the cows were synchronized and $\mathrm{PGF}_{2 \alpha}$ was injected on d 16 to 17 of the cycle. The interval from $\mathrm{PGF}_{2 \alpha}$ injection to behavioral estrus was longer in the E-FLAX group than in the E-SUN group, and the beginning of the luteal phase of the subsequent cycle was delayed. Concentrations of estradiol in follicular fluid of the preovulatory follicles were higher in the E-SUN group than in the E-FLAX group. The number of follicles aspirated by ovum pickup was higher in the E-FLAX group than in the control group, and the cleavage rate in the E-FLAX group was higher than in the control group, but not the E-SUN group. In conclusion, dietary n-3 fatty acids influenced the follicular status and increased the cleavage rate of oocytes as compared with those of control cows. These findings could be related to modifications of the fatty acid composition in plasma and ovarian compartments in response to dietary supplementation.

Key words: fatty acid composition, n-3, oocyte quality, preovulatory follicle

\section{INTRODUCTION}

Fatty acids (FA) have been recognized as major regulators of biological processes in various tissues; they are the main component of cell membranes, and the FA composition affects cell membrane functions (Abayasekara and Wathes, 1999). Among the FA, n-3 and $\mathrm{n}-6 \mathrm{FA}$ and the ratio between them are considered central factors in tissue functionality. The length of the carbon chain and the presence of the double bond on 3 carbon atoms in n-3 FA provide this type of FA unique 
biological capabilities. The n-3 FA are potent participants in the following biological processes: functioning of the immunological system (Prescott and Calder, 2004), blood coagulation and vascular resistance, enzyme activities, cell proliferation and differentiation, and receptor expression (Clandinin et al., 1991; Deckelbaum et al., 2006).

Diets with a lower n-6:n-3 ratio are considered healthier for human consumption, and there has been growing interest in decreasing this ratio in human diets. Linoleic (C18:2n-6) and linolenic (C18:3n-3) acids are the predominant polyunsaturated FA (PUFA) in the milk fat of dairy cows and in other tissues (Bilby et al., 2006a). Elongase and desaturase enzymes convert the C18:3n-3 to longer chain FA derivatives as eicosapentaenoic acid (EPA; C20:5n-3) and docosahexaenoic acid (DHA; C22:5n-3; Wathes et al., 2007).

Dietary fat has been shown to benefit the fertility of dairy cows (Staples et al., 1998; Santos et al., 2008). In recent years, it has become well accepted that the positive effects of fat supplementation stem from the provision of high quantities of specific FA, rather than by improving the energy status of the cow (Mattos et al., 2000). Fatty acids are involved in reproduction through 2 main processes: 1) FA are the precursors for steroid hormones (via cholesterol) and 2) FA are precursors for prostaglandins (via arachidonic acid). Dietary FA may also influence the functionality of reproductive tissues by changing cell membrane composition and, in consequence, membrane fluidity. Membrane fluidity can affect the transformation of nutrients and other biological factors in the cell and thus influence physiological functions of the tissue. Bilby et al. (2006a) fed cows fish oil (rich in n-3 FA) and observed an increase in the proportion of n-3 FA in various tissues, including the endometrium. A reduction in $\mathrm{PGF}_{2 \alpha}$ synthesis in cows fed fish meal was observed by Mattos et al. (2004), which was explained by an inhibitory effect of DHA and EPA on uterine tissues.

Several studies have investigated the effects of specific FA on follicular development, preovulatory follicle characteristics, or oocyte quality, and they have yielded inconsistent results. Altered follicle development has been caused by dietary FA in some studies: an increased number of medium-sized follicles was observed in cows fed diets rich in C18:2n-6 or C18:3n-3 (Robinson et al., 2002), whereas a lower number of small follicles was observed in cows supplemented with flaxseed (rich in C18:3n-3) than in cows fed soybeans (rich in C18:2n-6; Ponter et al., 2006).

The effects of supplementing particular FA on the characteristics of dominant follicles were also examined. The diameter of the dominant preovulatory follicle was increased in cows fed diets rich in C18:2n-6 (Robinson et al., 2002) or C18:3n-3 (Ambrose et al., 2006). In a previous study, we demonstrated higher concentrations of androstenedione $\left(\mathbf{A}_{4}\right)$ and estradiol $\left(\mathbf{E}_{2}\right)$ in preovulatory follicles of cows fed diets rich in C18:1n-9 and C18:2n-6 (Zachut et al., 2008). Furthermore, enhanced $\mathrm{E}_{2}$ concentrations in plasma during the follicular phase were observed in cows fed a diet rich in C18:3n-3, which is associated with dominant follicle steroidogenesis (Robinson et al., 2002).

In a study in which cows were fed a variety of monounsaturated FA (MUFA) and PUFA during the summer season, no influence was observed on the quality of oocytes collected by ovum pickup (OPU; Bilby et al., 2006b). Leroy et al. (2005) demonstrated adverse effects of the saturated FA palmitic (C16:0) and stearic (C18:0) on the cleavage rate and development rate of blastocysts in vitro. In a recent study, Cerri et al. (2009) observed a tendency for increased fertilization of oocytes and improved embryo quality in cows fed C18:2n-6 and C18:1-trans. These findings indicate distinct effects of specific FA on the quality and development of oocytes and embryos.

The objectives of this study were to determine the incorporation of encapsulated fat containing either $40.8 \%$ flaxseed oil or $40.8 \%$ sunflower oil (low or high n-6:n-3 ratio, respectively) in the diets of high-producing dairy cows into milk fat, plasma, and ovarian compartments as follicular fluid (FF), granulosa cells, and oocytes. Furthermore, because these changes in FA composition might influence developmental and physiological aspects of the ovarian compartments, we investigated the effects on follicular status, preovulatory follicle characteristics, and oocyte competence.

\section{MATERIALS AND METHODS}

\section{Cows and Diets}

The experimental protocol of the study was approved by the Volcani Center Animal Care Committee and was conducted at the Volcani Center experimental farm in Bet Dagan, Israel. Twenty-four multiparous Israeli Holstein dairy cows, averaging $114 \pm 24$ DIM and $620 \pm$ $22 \mathrm{~kg}$ of BW were group-housed in covered loose pens with adjacent outside yards, and had free access to water. The cows were stratified randomly within stratum, and strata were defined by the following parameters: milk production, DIM, and parity. The cows were assigned to 1 of 3 treatment groups: 1$)$ control $(n=7)$, in which cows were fed a typical Israeli lactating cow diet, which contained $1 \%$ of Ca salts of FA (DM basis); 2) EFLAX $(\mathrm{n}=8)$, in which cows were fed a lactating cow diet that consisted of $1 \mathrm{~kg} / \mathrm{d}$ per cow of encapsulated fat (3.8\% of dietary DM) containing $40.8 \%$ flaxseed oil, 
Table 1. Ingredients and chemical composition of the experimental diets

\begin{tabular}{|c|c|c|c|}
\hline \multirow[b]{2}{*}{ Item } & \multicolumn{3}{|c|}{ Treatment $^{1}$} \\
\hline & Control & E-FLAX & E-SUN \\
\hline \multicolumn{4}{|l|}{ Ingredient, $\%$ of $\mathrm{DM}$} \\
\hline Corn grain, ground & 15.0 & 10.3 & 10.3 \\
\hline Barley grain, rolled & 13.1 & 9.1 & 9.1 \\
\hline Rapeseed meal & 3.2 & 5.6 & 5.6 \\
\hline Soybean meal & 4.4 & 2.1 & 2.1 \\
\hline Sunflower meal & 4.6 & 7.5 & 7.5 \\
\hline Wheat bran & 3.0 & 12.6 & 12.6 \\
\hline Corn gluten feed & 6.6 & 1.6 & 1.6 \\
\hline Cottonseed & 4.4 & 0.9 & 0.9 \\
\hline Wheat silage & - & 11.3 & 11.3 \\
\hline Corn silage & 21.8 & 4.9 & 4.9 \\
\hline Dried distillers grain & 6.6 & - & - \\
\hline Vetch hay & 4.3 & 9.1 & 9.1 \\
\hline Oats hay & 8.9 & 9.4 & 9.4 \\
\hline Soybean oil & 0.2 & - & - \\
\hline Soybean hulls & - & 8.6 & 8.6 \\
\hline Ca salts of fatty acids & 1.0 & - & - \\
\hline Salt & 1.4 & 1.6 & 1.6 \\
\hline Urea & 0.3 & 0.3 & 0.3 \\
\hline Ca bicarbonate & 0.7 & 0.7 & 0.7 \\
\hline Vitamins and minerals $^{2}$ & 0.1 & 0.1 & 0.1 \\
\hline Limestone & 0.4 & 0.5 & 0.5 \\
\hline Encapsulated sunflower oil & - & - & 3.8 \\
\hline Encapsulated flaxseed oil & - & 3.8 & - \\
\hline \multicolumn{4}{|l|}{ Chemical composition } \\
\hline $\mathrm{NE}_{\mathrm{L}},{ }^{3} \mathrm{Mcal} / \mathrm{kg}$ & 1.75 & 1.75 & 1.75 \\
\hline $\mathrm{CP}, \%$ & 17.0 & 16.8 & 16.8 \\
\hline $\mathrm{NDF}, \%$ & 34.0 & 37.0 & 37.0 \\
\hline Ether extract, $\%$ & 4.7 & 5.4 & 5.4 \\
\hline $\mathrm{Ca}, \%$ & 0.9 & 0.9 & 0.9 \\
\hline $\mathrm{P}, \%$ & 0.4 & 0.4 & 0.4 \\
\hline
\end{tabular}

${ }^{1}$ Treatments: cows were fed a lactating cow diet (control); a lactating cow diet that consisted of $1 \mathrm{~kg} / \mathrm{d}$ per cow (3.8\% of dietary DM) of encapsulated flaxseed, providing $242.2 \mathrm{~g}$ of C18:3n-3 (E-FLAX); or a lactating cow diet that consisted of $1 \mathrm{~kg} / \mathrm{d}$ per cow (3.8\% of dietary DM) of encapsulated sunflower, providing $260.0 \mathrm{~g}$ of C18:2n-6 (E-SUN).

${ }^{2}$ Contained 20,000,000 IU of vitamin $\mathrm{A} / \mathrm{kg}, 2,000,000 \mathrm{IU}$ of vitamin $\mathrm{D} / \mathrm{kg}, 15,000 \mathrm{IU} / \mathrm{kg}$ of vitamin E, $6,000 \mathrm{mg} / \mathrm{kg}$ of $\mathrm{Mn}, 6,000 \mathrm{mg} / \mathrm{kg}$ of $\mathrm{Zn}, 2,000 \mathrm{mg} / \mathrm{kg}$ of Fe, $1,500 \mathrm{mg} / \mathrm{kg}$ of $\mathrm{Cu}, 120 \mathrm{mg} / \mathrm{kg}$ of I, $50 \mathrm{mg} / \mathrm{kg}$ of Se, and $20 \mathrm{mg} / \mathrm{kg}$ of $\mathrm{Co}$.

${ }^{3}$ Calculated using NRC (2001) values.

providing $242.2 \mathrm{~g}$ of C18:3n-3 (SILA, Venice, Italy); or 3) E-SUN ( $n=9)$, in which cows were fed a lactating cow diet that consisted of $1 \mathrm{~kg} / \mathrm{d}$ per cow of encapsulated fat (3.8\% of dietary DM) containing $40.8 \%$ sunflower oil, providing $260.0 \mathrm{~g}$ of C18:2n-6 (SILA). Both supplements were custom-made according to our requirements and were in pellet form (approximately 1 $\mathrm{mm}$ in diameter). The sunflower and flaxseed oils were mixed with carriers and then microencapsulated with vegetable fats by using a spray-cooling system.

The cows were fed in groups once a day at $1100 \mathrm{~h}$. The fat supplements were hand-mixed into the TMR, and the cows remained on the experimental dietary treatments until the end of the study. In each group, orts were collected and recorded twice a week.
Table 2. Fatty acid profile of the E_FLAX and E-SUN supplements (\% of total fatty acids)

\begin{tabular}{lrc}
\hline Fatty acid & E-FLAX & E-SUN \\
\hline C12:0 & 0.08 & 0.08 \\
C14:0 & 1.21 & 1.21 \\
C15:0 $16: 0$ & 0.12 & 0.12 \\
C17:0 & 16.46 & 17.22 \\
C18:0 & 0.43 & 0.43 \\
C18:1n-9 & 34.34 & 34.48 \\
C18:2n-6 & 7.88 & 12.35 \\
C18:3n-3 & 7.85 & 33.38 \\
C20:0 & 31.05 & 0 \\
Saturated & 0.58 & 0.74 \\
Monounsaturated & 52.64 & 53.54 \\
Polyunsaturated & 7.88 & 12.35 \\
n-3 & 39.48 & 34.12 \\
n-6 & 31.05 & 0 \\
\hline
\end{tabular}

Chemical composition and ingredients of the 3 diets are presented in Table 1. The diets were formulated to be isoenergetic. Samples of the TMR were collected every other week and DM and chemical composition were determined. Both supplements contained 38.8\% vegetable oil, $40.8 \%$ flaxseed or sunflower oil, and $20.4 \%$ minerals (DM basis). The FA composition of the supplements is provided in Table 2. The calculated FA composition of the main sources of fat in the control $\operatorname{diet}$ (Ca salts of FA and cottonseed) was $0.4 \% \mathrm{C} 14: 0$, 34.7\% C16:0, 0.4\% C16:1, 3.8\% C18:0, 29.5\% C18:1, $27.6 \%$ C18:2n-6, 0.09\% C18:3n-3, and 2.6\% other FA.

Cows were milked 3 times daily, and milk production and $\mathrm{BW}$ were recorded electronically at each milking (SAE Afikim, Kibbutz Afikim, Israel). Milk samples were collected every $3 \mathrm{wk}$, beginning $10 \mathrm{~d}$ after dietary treatments commenced, from 3 consecutive milkings for determination of fat, protein, lactose, and urea. Milk composition was determined by infrared analysis (standard IDF 141C; International Dairy Federation, 2000) at the laboratories of the Israeli Cattle Breeders Association (Caesarea, Israel). The milk fat, protein, and lactose yields were calculated by multiplication of milk yield and the fat, protein, and lactose percentages, respectively. In 2 collections during the study (54 and $110 \mathrm{~d}$ after commencement of dietary treatments), additional milk samples were taken for analysis of milk FA composition.

\section{Experimental Design}

Before the beginning of dietary supplementation, the ovaries of the cows were monitored twice ( $5 \mathrm{~d}$ apart) by ultrasonography with a $5-\mathrm{MHz}$ linear array transducer (Aquila, Pie Medical, Maastracht, the Netherlands) to evaluate the cyclic status of the ovaries; cows with a large persistent follicle $(>24 \mathrm{~mm})$ or smooth ovaries in 


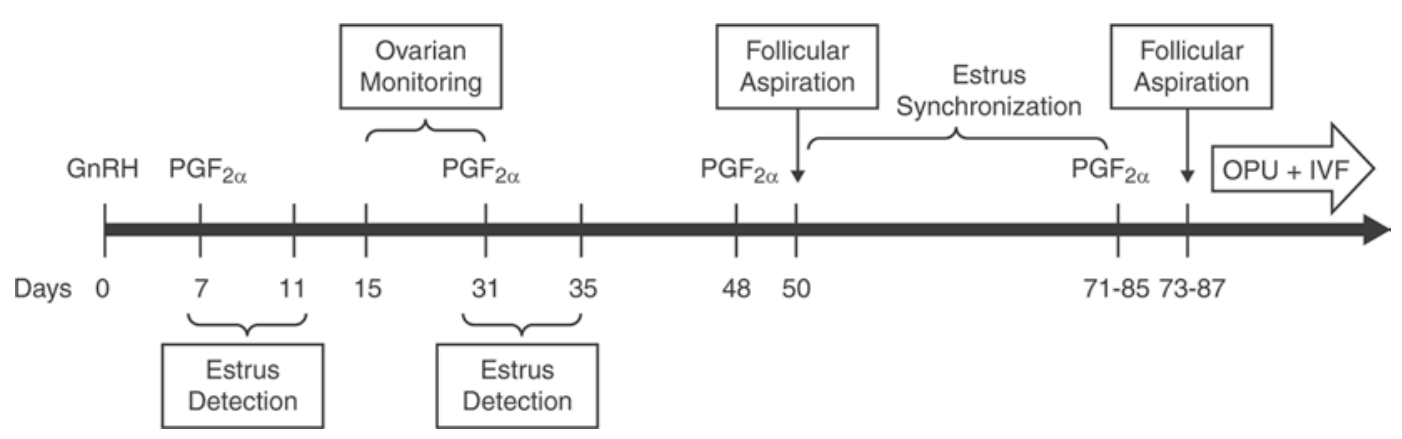

Figure 1. Schematic representation of the experiment schedule. All cows were given GnRH on d 0 (17 d after the commencement of dietary treatments) and $\mathrm{PGF}_{2 \alpha}$ on $\mathrm{d} 7$. Cows were examined for signs of estrus ( 7 to 11 ), and from $5 \mathrm{~d}$ after visible estrus (d 15), ovaries were monitored for follicular development. At d 16 of the estrus cycle (d 31), $\mathrm{PGF}_{2 \alpha}$ was injected and cows were monitored for signs of estrus (d 31 to 35 ). Fifteen days after behavioral estrus (d 48), another $\mathrm{PGF}_{2 \alpha}$ injection was given, and $48 \mathrm{~h}$ later, follicles were aspirated. The estrous cycle of the cows was resynchronized and a second follicular aspiration was conducted (d 73 to 87). Sessions of ovum pickup (OPU) and in vitro fertilization (IVF) were conducted twice a week until the cessation of dietary treatments.

both subsequent screenings were not included in the study, whereas the rest of the cows participated in the study. The estrous cycles of cows that had ovaries with a normal appearance but did not have a corpus luteum (CL) were presynchronized. These cows were treated intramuscularly with GnRH analog (0.02 $\mathrm{mg}$ of buserelin; Receptal, Intervet International BV, Boxmeer, the Netherlands) to stimulate ovulation and subsequently CL development, which was followed 7 d later with a $\mathrm{PGF}_{2 \alpha}$ injection $(2.5 \mathrm{~mL}$ of Estrumate, Coopers Animal Health Ltd., Berkhamsted, UK) to cause luteolysis.

Estrous Cycle Synchronization and Ultrasound Evaluation of the Ovarian Structures. A schematic schedule of the experiment is presented in Figure 1. Seventeen days after the dietary treatments commenced, all cows were administered GnRH intramuscularly, and $7 \mathrm{~d}$ later their ovaries were monitored by ultrasound for the presence of CL. Cows with CL on the ovaries (22 out of 24) were treated with $\mathrm{PGF}_{2 \alpha}$. Cows that manifested behavioral estrus after the $\mathrm{PGF}_{2 \alpha}$ injection (19 out of 22 cows) were used to determine ovarian follicular status, and the estrous cycles of the remaining 3 cows were resynchronized.

The ovaries of each cow were monitored for follicular status on d 5, 9, 13, and 16 of the estrous cycle by transrectal ultrasonography. Follicles that were $\geq 2 \mathrm{~mm}$ in diameter were recorded and an ovarian map was drawn for each cow. The follicles were classified into 3 subclasses based on diameter: class 1 was 2 to $5 \mathrm{~mm}$; class 2 was 6 to $9 \mathrm{~mm}$; and class 3 was $\geq 10 \mathrm{~mm}$. Blood samples were taken 3 times a week (Sunday, Tuesday, and Thursday) to monitor progesterone $\left(\mathbf{P}_{4}\right)$ concentrations in plasma during the estrous cycle. On d 16 to 17 of the estrous cycle, ovaries were monitored for the presence of CL and the cows were treated with $\mathrm{PGF}_{2 \alpha}$ to induce luteolysis and ovulation. The CL diameter (including the cavity) was determined on the day of
$\mathrm{PGF}_{2 \alpha}$ injection and $48 \mathrm{~h}$ later, to confirm regression of the CL.

During the entire study, the activity of the cows was recorded automatically 3 times a day with pedometers (Computerized Dairy Management Systems, SAE Afikim). In each cycle, the individual daily average activity $7 \mathrm{~d}$ before the $\mathrm{PGF}_{2 \alpha}$ injection and $2 \mathrm{~d}$ later were defined as baseline data, and the subsequent daily activity of each cow was calculated as the deviation (\%) from the average baseline data. Three visual observations per day for behavioral estrus detection were also conducted from d 1 to 5 after the $\mathrm{PGF}_{2 \alpha}$ injection.

Aspiration of Large Follicles. At 14 to $15 \mathrm{~d}$ after behavioral estrus, cows received another $\mathrm{PGF}_{2 \alpha}$ injection, and $48 \mathrm{~h}$ later, the FF from follicles $>7 \mathrm{~mm}$ in diameter was aspirated as described previously (Moallem et al., 2007). Briefly, cows were sedated with an intramuscular injection of $1 \mathrm{~mL}$ of $2 \%$ Rompun (xylazine base, $20 \mathrm{mg} / \mathrm{mL}$; XYL-M2 Veterinary, VMD, Arendonk, Belgium) and were given a local anesthesia in the form of $5 \mathrm{~mL}$ of $2 \%$ lidocaine $\mathrm{HCl}(200 \mathrm{mg} / 10$ $\mathrm{mL}$; Esracain 2\%, Rafa Laboratories, Jerusalem, Israel) injected epidurally between the last sacral and first caudal vertebrae. Follicles were aspirated separately using an ultrasound scanner (Pie Medical) connected to a $7.5-\mathrm{MHz}$ vaginal sector transducer equipped with a needle guide and connected to a suction pump (MP86, Biometra, Goettingen, Germany) set at a flow rate of 25 to $30 \mathrm{~mL} / \mathrm{min}$. The needles used were 18 gauge and were changed between follicles. After collection, FF was centrifuged for $15 \mathrm{~min}$, the sediment that included granulosa cells was separated from fluids, and both fractions were frozen at $-18^{\circ} \mathrm{C}$ until analysis.

Seven days after FF aspiration, the estrous cycle of the cows was resynchronized as follows: the cows were treated intramuscularly with $\mathrm{GnRH}$, and $7 \mathrm{~d}$ later, ovaries were monitored by ultrasound for the presence of 
CL. Cows with a visible CL on the ovaries were given a $\mathrm{PGF}_{2 \alpha}$ injection to induce luteolysis and ovulation; on d 15 after estrus, the cows were re-treated with $\mathrm{PGF}_{2 \alpha}$, and $48 \mathrm{~h}$ later, a second session of $\mathrm{FF}$ aspiration was conducted. In both aspirations, blood samples were collected on the day of $\mathrm{PGF}_{2 \alpha}$ administration and on the day of aspiration to ensure a response and for determination of plasma FA composition.

OPU Procedure and Oocyte Collection. Commencing $94 \mathrm{~d}$ from the beginning of dietary supplementation, transvaginal follicular aspiration was performed twice weekly ( 5 cows per treatment) according to the method of Roth et al. (2001). Cows were sedated with an intramuscular injection of $1 \mathrm{~mL}$ of $2 \%$ Rompun (xylazine base, $20 \mathrm{mg} / \mathrm{mL}$; XYL-M2 Veterinary, VMD) and were given a local anesthesia of $5 \mathrm{~mL}$ of $2 \%$ lidocaine $\mathrm{HCl}$ (200 mg/10 mL; Esracain 2\%, Rafa Laboratories) injected epidurally between the last sacral and first caudal vertebrae. Follicles were aspirated using an ultrasound scanner (Pie Medical) connected to a $7.5-\mathrm{MHz}$ vaginal sector transducer equipped with a needle guide and connected to a suction pump. For each cow in each session, follicular contents from all visible 3- to 7-mm follicles were collected into a single $50-\mathrm{mL}$ tube that contained HEPES-Tyrode's lactate solution medium (Sigma-Aldrich Israel Ltd., Rehovot, Israel) supplemented with antibiotics and $0.008 \%$ heparin (SigmaAldrich Israel Ltd.), in 0.4\% BSA (Sigma-Aldrich Israel Ltd.). The tubes with the aspirated follicular content were transferred to an adjacent laboratory; recovered cumulus-oocyte complexes (COC) were counted and examined morphologically. Oocytes were classified into 4 categories according to the number of layers of the cumulus surrounding the oocytes and their cytoplasmic consistency, as described elsewhere (de Loos et al., 1989): grade 1, spherical, symmetrical, and intact oocytes of uniform size, color, and texture, entirely surrounded by 3 to 5 compact layers of cumulus cells; grade 2 , incomplete cumulus layer, oocyte partially denuded; grade 3, cumulus expanded, oocyte denuded, partially degenerated cumulus; and grade 4, totally degenerated cumulus and oocyte.

In 2 sessions, oocytes of grades 1 and 2 were collected for FA profile analysis. Because the individual oocyte lipid mass was well below the sensitivity of the analytical method, COC were analyzed in groups of approximately 30 oocytes in 2 replicates per treatment.

Oocyte Maturation. The procedure for oocyte maturation and fertilization was performed according to the method of Roth et al. (2001). Briefly, after the oocytes had been recovered and graded, all COC were washed with oocyte wash buffer (K-SIWB, Cook, Sydney, Australia), transferred separately for each treatment group into 4-well culture multidishes (Nunc,
Roskilde, Denmark) containing $500 \mu \mathrm{L}$ of maturation medium (TCM-199, Sigma-Aldrich Israel Ltd.), and incubated for $22 \mathrm{~h}$ at $38.5^{\circ} \mathrm{C}$ in $5 \% \mathrm{CO}_{2}$ in humidified air.

In Vitro Fertilization. Cumulus-oocyte complexes were washed once in HEPES-Tyrode's albumin, lactate, and pyruvate (Sigma-Aldrich Israel Ltd.) after maturation, denuded of cumulus cells mechanically by pipette, and placed in their respective groups in 4-well plates containing $500 \mu \mathrm{L}$ of In Vitro Fert (Cook) per well, with $0.0005 \%$ heparin. Semen from a single bull was added to each well to a final concentration of $1 \times 10^{6}$ spermatozoa $/ \mathrm{mL}$. After the addition of sperm, $20 \mu \mathrm{L}$ of a solution of $0.5 \mathrm{mM}$ penicillamine (Sigma-Aldrich Israel Ltd.), $0.25 \mathrm{~m} M$ hypotaurine (Sigma-Aldrich Israel Ltd.), and $25 \mu M$ epinephrine (Sigma-Aldrich Israel Ltd.) in $0.9 \%$ (wt/vol) $\mathrm{NaCl}$ was added to each well. Sperm and COC were coincubated for $16 \mathrm{~h}$ at $38.5^{\circ} \mathrm{C}$ in $5 \% \mathrm{CO}_{2}, 5 \% \mathrm{O}_{2}$, and $90 \% \mathrm{~N}_{2}$ in humidified air. Presumptive zygotes were washed once in In Vitro Cleave (Cook) and were then placed into $50-\mu \mathrm{L}$ culture drops of In Vitro Cleave (5 to 10 oocytes per drop). Oocytes were cultured at $38.5^{\circ} \mathrm{C}$ in $5 \% \mathrm{O}_{2}, 5 \% \mathrm{CO}_{2}$, and $90 \% \mathrm{~N}_{2}$ in humidified air for another $22 \mathrm{~h}$. The proportion of oocytes that cleaved, and the proportions of embryos at the 2-, 3-, and 4-cell stages were recorded $40 \mathrm{~h}$ postinsemination.

\section{Hormone Analysis}

Concentrations of $\mathrm{P}_{4}$ and $\mathrm{E}_{2}$ in $\mathrm{FF}$ were determined by RIA (Diagnostic Products, Los Angeles, CA), as were FF $\mathrm{A}_{4}$ concentrations (Diagnostic Systems Laboratories, Webster, TX). All FF samples were diluted 100,500 , or 30 times for $\mathrm{P}_{4}, \mathrm{E}_{2}$, and $\mathrm{A}_{4}$ assays, respectively, to fit the range of detection. The minimal detectable amounts were $0.2,20$, and $0.1 \mathrm{ng} / \mathrm{mL}$ for $\mathrm{P}_{4}$, $\mathrm{E}_{2}$, and $\mathrm{A}_{4}$, respectively. The intra- and interassay coefficients of variation for the $\mathrm{P}_{4}$ assay were 9.2 and $8.5 \%$, respectively. The intra- and interassay coefficients of variation for the $\mathrm{E}_{2}$ assay were 4.1 and $3.6 \%$, and those for the $\mathrm{A}_{4}$ assay were 6.1 and $4.5 \%$, respectively. Follicles were regarded as $\mathrm{E}_{2}$-active when the $\mathrm{E}_{2}: \mathrm{P}_{4}$ ratio was $>1$ (Ireland and Roche, 1982), and these follicles were then subjected to further analysis.

\section{FA Composition of Plasma, Milk Fat, and Ovarian Compartments}

Fatty acids in plasma, FF, granulosa cells, and COC were extracted as described by Moallem et al. (1999). Briefly, the samples were saponified in a mixture of $60 \%$ $\mathrm{KOH}$ and ethanol, and then extracted with petroleum ether and methylated with $5 \% \mathrm{H}_{2} \mathrm{SO}_{4}$ in methanol. 
Analysis of FA was performed with a 5890 series 2 gas chromatograph (Agilent Technologies, Wilmington, DE) equipped with a capillary column $(30 \mathrm{~m} \times 0.53 \mathrm{~mm}$, $0.5 \mathrm{~mm}$; Agilent Technologies, Santa Clara, CA) and a flame-ionization detector. The column was maintained at $160^{\circ} \mathrm{C}$ isothermal. Nitrogen was used as the carrier gas with a linear velocity of $22 \mathrm{~cm} / \mathrm{s}$; the injection volume was $2 \mu \mathrm{L}$. The injection port was maintained at $230^{\circ} \mathrm{C}$ and the detector was maintained at $235^{\circ} \mathrm{C}$. Detector air flow was $400 \mathrm{~mL} / \mathrm{min}$ and hydrogen flow was $33 \mathrm{~mL} / \mathrm{min}$.

The milk FA profile was examined after extraction (method 996.06; AOAC, 1995), and gas chromatographic analysis was performed at Milouda Laboratories (Haifa, Israel) with an Agilent 6890N gas chromatograph (Agilent Technologies) equipped with a Quadrex capillary column $(60 \mathrm{~m} \times 0.25 \mathrm{~mm}, 0.25 \mu \mathrm{m}$; Quadrex, Woodbridge, CT) and a flame-ionization detector. The initial temperature of the column was set at $60^{\circ} \mathrm{C}$, with the temperature increased by $5^{\circ} \mathrm{C} / \mathrm{min}$ and then maintained at $225^{\circ} \mathrm{C}$ for the remainder of the analysis. Hydrogen was used as the carrier gas with a linear velocity of 1.6 $\mathrm{m} / \mathrm{min}$; the injection volume was $1 \mu \mathrm{L}$, with a split ratio of $1: 100$.

\section{Statistical Analyses}

Continuous variables (milk and milk solids, number of follicles during monitoring of ovaries, and $\mathrm{P}_{4}$ concentrations) were analyzed as repeated measurements with the MIXED procedure of SAS (version 8.1; SAS Institute, 2000). The corresponding data on milk and milk solids from the 10-d period before dietary treatments commenced were used as covariables.

The model used was

$$
\mathrm{Y}_{\mathrm{ijkl}}=\mu+\mathrm{T}_{\mathrm{i}}+\mathrm{L}_{\mathrm{j}}+\mathrm{C}(\mathrm{T} \times \mathrm{L})_{\mathrm{ijk}}+\mathrm{DIM}_{\mathrm{ijkl}}+E_{\mathrm{ijklm}},
$$

where $\mu$ is the overall mean; $T_{i}$ is the treatment effect $(\mathrm{i}=1$ to 3$) ; \mathrm{L}_{\mathrm{j}}$ is the parity $(\mathrm{j}=2$ or $>2) ; \mathrm{C}(\mathrm{T} \times \mathrm{L})_{\mathrm{ijk}}$ is cow $\mathrm{k}$ nested in treatment $\mathrm{i}$ and cow nested in parity $\mathrm{j}$; $\mathrm{DIM}_{\mathrm{ijkl}}$ is DIM as a continuous variable; and $E_{\mathrm{ijklm}}$ is the random residual.

For the number of follicles during monitoring of ovaries and $\mathrm{P}_{4}$ concentration analysis, the day in the cycle was used as a continuous variable. The hormone concentrations in FF and the deviation in activity were analyzed with the GLM procedure of SAS (version 8.1; SAS Institute, 2000).

Number of follicles, oocyte number and grade, and oocyte recovery rate were calculated for each cow and analyzed using the MIXED procedure of SAS (version 8.1; SAS Institute, 2000). The model included the effects of treatment, cow (nested in treatment), and the treatment $\times$ session interaction. For matured oocytes and cleavage rate, sessions were considered random effects and data were analyzed with the MIXED procedure. The model included treatment, session, and the treatment $\times$ session interaction.

The FA profiles were analyzed using the GLM procedure of SAS (SAS Institute, 2000). Least squares means and adjusted standard errors of the means are presented in the tables. A value of $P<0.05$ was accepted as statistically significant unless otherwise stated, and tendencies were reported at $0.05<P<0.10$.

\section{RESULTS}

\section{Milk and Milk Components}

The milk and milk solids data are presented in Table 3 . The average milk production did not differ between the control and E-FLAX groups, but was lower in the E-SUN group as compared with the other groups $(P<$ 0.0001). Milk fat percentage was higher in the E-FLAX group than in the E-SUN and control groups $(P<0.02)$; however, milk fat yield was not affected by treatments and FCM $(3.5 \%)$ did not differ between groups. Milk protein percentage and yield were lower in the E-FLAX group than in the E-SUN and control groups $(P<0.03$ and $P<0.02$, respectively). Milk lactose percentage was lower in the E-SUN group than in the E-FLAX and control groups $(P<0.02)$; however, lactose yield was lower in the E-FLAX group than in the E-SUN and control groups $(P<0.04)$. Milk urea concentrations did not differ between groups $(P>0.05)$. The average group DMI, expressed as a percentage of BW, was $4.2 \%$, with no differences between groups.

\section{FA Composition of Milk}

The effect of the nutritional treatments on milk fat FA composition is presented in Table 4. The proportion of C16:0 was higher in the control group than in the E-FLAX and E-SUN groups $(P<0.009)$. The proportion of C18:2n-6 in the milk fat of cows fed ESUN was 31 and $46 \%$ higher than that in the control and E-FLAX group, respectively $(P<0.01)$. Feeding E-FLAX increased the proportions of C18:3n-3 $(P<$ $0.001)$, C20:5n-3 $(P<0.001)$, and $\mathrm{C} 22: 5 n-3(P<0.02)$ in milk fat as compared with the other 2 groups. The proportion of PUFA in milk fat of the E-SUN group was higher than that in the control group $(P<0.02)$, and in the E-FLAX group, it tended to be higher than in the control group $(P<0.06)$. The $\mathrm{n}-3 \mathrm{FA}$ concentration was 5.8 times higher in the E-FLAX group than in the control group and was 4.6 times higher than in the ESUN group $(P<0.0003)$. The proportion of $n-6$ FA was 
Table 3. Least squares means of milk and milk solids production during the experiment

\begin{tabular}{lcccc}
\hline & \multicolumn{3}{c}{ Treatment $^{1}$} \\
\cline { 2 - 4 } Item & Control & E-FLAX & E-SUN & SEM \\
\hline Milk, kg & $38.9^{\mathrm{a}}$ & $38.5^{\mathrm{a}}$ & $36.7^{\mathrm{b}}$ & 0.17 \\
$3.5 \%$ FCM, kg & 38.1 & 37.5 & 37.1 & 0.76 \\
Fat, \% & $3.3^{\mathrm{b}}$ & $3.6^{\mathrm{a}}$ & $3.4^{\mathrm{b}}$ & 0.08 \\
Protein, \% & $3.4^{\mathrm{a}}$ & $3.1^{\mathrm{b}}$ & $3.2^{\mathrm{a}}$ & 0.04 \\
Lactose, \% & $4.8^{\mathrm{a}}$ & $4.8^{\mathrm{a}}$ & $4.7^{\mathrm{b}}$ & 0.02 \\
Fat, kg & 1.32 & 1.32 & 1.28 & 0.03 \\
Protein, kg & $1.29^{\mathrm{a}}$ & $1.14^{\mathrm{c}}$ & $1.22^{\mathrm{b}}$ & 0.02 \\
Lactose, kg & $1.30^{\mathrm{a}}$ & $1.15^{\mathrm{b}}$ & $1.21^{\mathrm{a}}$ & 0.02 \\
Urea, g/dL & 0.03 & 0.03 & 0.03 & 0.002 \\
\hline
\end{tabular}

${ }^{\mathrm{a}-\mathrm{c}}$ Within rows, means with different superscript letters are statistically different, $P<0.05$.

${ }^{1}$ Treatments: cows were fed a lactating cow diet (control); a lactating cow diet that consisted of $1 \mathrm{~kg} / \mathrm{d}$ per cow (3.8\% of dietary DM) of encapsulated flaxseed, providing $242.2 \mathrm{~g}$ of C18:3n-3 (E-FLAX); or a lactating cow diet that consisted of $1 \mathrm{~kg} / \mathrm{d}$ per cow (3.8\% of dietary DM) of encapsulated sunflower, providing $260.0 \mathrm{~g}$ of C18:2n-6 (E-SUN).

higher in the E-SUN group than in the other 2 groups $(P<0.01)$. The n-6:n-3 ratio in milk fat was reduced from 15.2 in the control group and 16.0 in the E-SUN group to 2.4 in the E-FLAX group $(P<0.0001)$.

\section{FA Composition of Plasma}

The FA C18:2n-6 was the predominant FA in plasma (approximately 50\%), and the proportion of this FA was lower in the E-FLAX group than in the other 2 groups (Table $5 ; P<0.003$ ). The proportion of C18:3n-3 increased dramatically by feeding E-FLAX, from 1.43 and 1.49 in the control and E-SUN groups, respectively, to 7.98 in the E-FLAX group $(P<0.0001)$. The proportions of $\mathrm{C} 20: 3 \mathrm{n}-6$ and $\mathrm{C} 20: 4 \mathrm{n}-6$ were lower in the E-FLAX group than in the other 2 groups $(P<0.004)$. No differences were observed among groups in saturated FA (SFA) and PUFA concentration, but the proportion of MUFA was higher in the control group than in the other 2 groups $(P<0.01)$. The proportion of total n- 6 FA was lower in the E-FLAX group than in the control and E-SUN groups $(P<0.0002)$, and the $\mathrm{n}-6$ :n-3 ratio was dramatically decreased in the E-FLAX group (from approximately 42 in the control and E-SUN groups to 6.74 in the E-FLAX group; $P<0.0001)$.

\section{FA Composition of FF}

The profile of FA in FF is presented in Table 6, and in general, the proportion of FA in FF was similar to that observed in plasma. The predominant $\mathrm{FA}$ in $\mathrm{FF}$ was C18:2n-6, and it was higher in the E-SUN group than in the other 2 groups $(P<0.04)$. As in plasma and milk fat, the proportion of $\mathrm{C} 18: 3 \mathrm{n}-3$ was enhanced considerably in the E-FLAX group as compared with the other 2 groups (from 1.4 to $7.25 ; P<0.0001$ ). The proportions of C20:3n- 6 and C20:4n- 6 were lower in the E-FLAX group than in the other 2 groups $(P<$ $0.0006)$. The proportion of total n- 6 FA was higher in the E-SUN group than in the E-FLAX group $(P<0.01)$ and tended to be higher than in the control group $(P$ $<0.08)$. Furthermore, the n-6:n-3 ratio was decreased from approximately 42 in the control and E-SUN groups to 7.18 in the E-FLAX group $(P<0.0001)$.

\section{FA Composition of Granulosa Cells}

The profiles of FA in granulosa cells that were aspirated in vivo from preovulatory follicles are presented in Table 7. The FA C16:0, which was predominant in granulosa cells, was lower in the E-FLAX group than in the control group $(P<0.03)$ and tended to be lower than in the E-SUN group $(P<0.08)$. The proportion of C18:2n-6 was higher in the E-FLAX group than in the E-SUN group $(P<0.05)$ and tended to be higher than in the control group $(P<0.1)$. The proportion of C18:3n-3 in granulosa cells in the E-FLAX group was approximately 5 -fold higher than those in the E-SUN and control groups $(P<0.0005)$. The proportion of SFA in the E-FLAX group tended to be lower than in the control group $(P<0.08)$. The proportion of PUFA in the granulosa cells of cows fed E-FLAX was $49 \%$ higher than in the other 2 groups $(P<0.05)$. The $\mathrm{n}-6$ FA were higher in the E-FLAX group than in the ESUN group $(P<0.05)$ and tended to be higher than in the control group $(P<0.09)$. The n-6:n-3 ratio in granulosa cells was lower in the E-FLAX group than in the other 2 groups $(P<0.01)$.

\section{FA Composition of COC}

The COC from grade 1 and 2 oocytes were analyzed for FA profile and the results are presented in Table 8 . The predominant FA in COC was C16:0, followed by C18:0. The proportion of C18:0 was numerically higher (71\%) in the E-FLAX group than in the other groups. The C18:2n-6 in the E-SUN group was numerically higher $(54 \%)$ than that in the E-FLAX group and was 2.4-fold higher than that in the control group. The FA C18:3n-3 was detected in the E-FLAX group (4.73\%), but not in the other groups.

\section{Ovarian Structures and Response to Estrous Cycle Synchronization}

The average numbers of class 1 follicles on d 5 and 9 of the cycle were higher in the E-FLAX group than in the E-SUN group, whereas no differences were observed 
Table 4. Least squares means of fatty acid profile in milk fat (\% of total fatty acids)

\begin{tabular}{|c|c|c|c|c|c|}
\hline \multirow[b]{2}{*}{ Fatty acid } & \multicolumn{3}{|c|}{ Treatment $^{1}$} & \multirow[b]{2}{*}{$P$-value } & \multirow[b]{2}{*}{ SEM } \\
\hline & Control & E-FLAX & E-SUN & & \\
\hline C4:0 & 2.10 & 1.34 & 1.30 & NS & 0.89 \\
\hline C6:0 & 1.45 & 1.55 & 1.47 & NS & 0.04 \\
\hline C8:0 & $0.95^{\mathrm{a}}$ & $0.92^{\mathrm{ab}}$ & $0.86^{\mathrm{b}}$ & $*$ & 0.02 \\
\hline C10:0 & 1.36 & 2.56 & 2.32 & NS & 0.78 \\
\hline C10:1 & $0.17^{\mathrm{a}}$ & $0.16^{\mathrm{a}}$ & $0.14^{\mathrm{b}}$ & $* *$ & 0.004 \\
\hline $\mathrm{C} 12: 0$ & $3.36^{\mathrm{a}}$ & $3.01^{\mathrm{b}}$ & $2.79^{\mathrm{c}}$ & $* *$ & 0.03 \\
\hline C14:0 & 10.46 & 10.79 & 10.58 & NS & 0.16 \\
\hline C14:1 & $0.74^{\mathrm{a}}$ & $0.55^{\mathrm{b}}$ & $0.53^{\mathrm{b}}$ & $*$ & 0.03 \\
\hline C15:0 & 0.86 & 0.88 & 0.86 & NS & 0.04 \\
\hline C15:1 & 0.58 & 0.29 & 0.28 & NS & 0.20 \\
\hline C16:0 & $28.70^{\mathrm{a}}$ & $27.71^{\mathrm{b}}$ & $27.30^{\mathrm{b}}$ & $*$ & 0.12 \\
\hline C16:1 & $1.67^{\mathrm{a}}$ & $1.38^{\mathrm{b}}$ & $1.46^{\mathrm{b}}$ & $*$ & 0.05 \\
\hline C17:0 & $0.46^{\mathrm{b}}$ & $0.54^{\mathrm{a}}$ & $0.54^{\mathrm{a}}$ & $*$ & 0.02 \\
\hline C17:1 & 0.22 & 0.22 & 0.23 & NS & 0.01 \\
\hline C18:0 & 1.48 & 13.81 & 13.14 & NS & 0.67 \\
\hline C18:1n-9 & 27.82 & 26.47 & 27.84 & NS & 0.62 \\
\hline C18:2n-6 & $4.60^{\mathrm{b}}$ & $4.15^{\mathrm{b}}$ & $6.07^{\mathrm{a}}$ & $* *$ & 0.19 \\
\hline $\mathrm{C} 18: 2 \mathrm{cis}$ & 0.73 & 0.61 & 0.80 & NS & 0.05 \\
\hline C18:3n-6 & 0.00 & 0.01 & 0.00 & NS & 0.00 \\
\hline C18:3n-3 & $0.25^{\mathrm{b}}$ & $1.65^{\mathrm{a}}$ & $0.32^{\mathrm{b}}$ & $* * *$ & 0.08 \\
\hline C18:4n-3 & 0.02 & 0.03 & 0.03 & NS & 0.01 \\
\hline C19:1 & $0.13^{\mathrm{a}}$ & $0.12^{\mathrm{a}}$ & $0.11^{\mathrm{b}}$ & $*$ & 0.002 \\
\hline C20:0 & $0.16^{\mathrm{b}}$ & $0.23^{\mathrm{a}}$ & $0.20^{\mathrm{a}}$ & * & 0.01 \\
\hline C20:1n-9 & $0.11^{\mathrm{b}}$ & $0.12^{\mathrm{a}}$ & $0.09^{c}$ & $* *$ & 0.002 \\
\hline C20:2n-6 & $0.04^{\mathrm{c}}$ & $0.23^{\mathrm{a}}$ & $0.07^{\mathrm{b}}$ & $*$ & 0.008 \\
\hline C20:3n-6 & $0.16^{\mathrm{ab}}$ & $0.06^{\mathrm{b}}$ & $0.19^{\mathrm{a}}$ & $*$ & 0.02 \\
\hline C20:4n-6 & $0.22^{\mathrm{a}}$ & $0.16^{\mathrm{b}}$ & $0.22^{\mathrm{a}}$ & $* *$ & 0.01 \\
\hline C20:5n-3 & $0.02^{\mathrm{b}}$ & $0.09^{\mathrm{a}}$ & $0.02^{\mathrm{b}}$ & $* * *$ & 0.003 \\
\hline C21:0 & 0.02 & 0.05 & 0.03 & NS & 0.02 \\
\hline $\mathrm{C} 22: 0$ & $0.04^{\mathrm{b}}$ & $0.05^{\mathrm{b}}$ & $0.07^{\mathrm{a}}$ & * & 0.005 \\
\hline C22:3n-6 & 0.00 & 0.00 & 0.01 & NS & 0.007 \\
\hline $\mathrm{C} 22: 5 \mathrm{n}-3$ & $0.04^{\mathrm{b}}$ & $0.12^{\mathrm{a}}$ & $0.04^{\mathrm{b}}$ & $*$ & 0.01 \\
\hline C22:6n-3 & 0.00 & 0.02 & 0.00 & NS & 0.01 \\
\hline $\mathrm{C} 23: 0$ & $0.00^{\mathrm{b}}$ & $0.06^{\mathrm{a}}$ & $0.00^{\mathrm{b}}$ & $* * *$ & 0.002 \\
\hline C24:0 & 0.00 & 0.01 & 0.03 & NS & 0.007 \\
\hline $\mathrm{C} 24: 1 \mathrm{n}-9$ & $0.06^{\mathrm{ab}}$ & $0.04^{\mathrm{b}}$ & $0.08^{\mathrm{a}}$ & $*$ & 0.007 \\
\hline C4:0 to C15:0 & 22.02 & 22.06 & 21.13 & NS & 1.42 \\
\hline Saturated & 62.80 & 63.52 & 61.49 & NS & 0.72 \\
\hline MUFA $^{2}$ & 31.13 & 29.34 & 30.74 & NS & 0.69 \\
\hline PUFA $^{3}$ & $6.07^{\mathrm{b}}$ & $7.14^{\mathrm{ab}}$ & $7.78^{\mathrm{a}}$ & $*$ & 0.26 \\
\hline$n-3$ & $0.33^{\mathrm{b}}$ & $1.90^{\mathrm{a}}$ & $0.41^{\mathrm{b}}$ & $* * *$ & 0.05 \\
\hline$n-6$ & $5.01^{\mathrm{b}}$ & $4.62^{\mathrm{b}}$ & $6.57^{\mathrm{a}}$ & $* *$ & 0.20 \\
\hline$n-6: n-3$ & $15.15^{\mathrm{a}}$ & $2.43^{\mathrm{b}}$ & $15.96^{\mathrm{a}}$ & $* * *$ & 0.33 \\
\hline
\end{tabular}

\footnotetext{
${ }^{\mathrm{a}-\mathrm{c}}$ Within rows, means with different superscript letters are statistically different.

${ }^{1}$ Treatments: cows were fed a lactating cow diet (control); a lactating cow diet that consisted of $1 \mathrm{~kg} / \mathrm{d}$ per cow (3.8\% of dietary DM) of encapsulated flaxseed, providing $242.2 \mathrm{~g}$ of C18:3n-3 (E-FLAX); or a lactating cow diet that consisted of $1 \mathrm{~kg} / \mathrm{d}$ per cow (3.8\% of dietary DM) of encapsulated sunflower, providing $260.0 \mathrm{~g}$ of C18:2n-6 (E-SUN).

${ }^{2}$ Monounsaturated fatty acids.

${ }^{3}$ Polyunsaturated fatty acids.

$* P<0.05 ;{ }^{* *} P<0.01$; *** $P<0.001$.
}

between the control group and the other 2 groups $(6.8$, 4.6 , and 5.8 follicles for E-FLAX, E-SUN, and the control, respectively; pooled SEM $=0.8 ; P<0.05)$. No differences were observed between treatment groups in the average numbers of class 2 follicles. The average numbers of class 3 follicles on d 5, 9, and 13 were higher in the E-SUN group than in the other 2 groups (1.4, 0.9 , and 1.0 follicles for E-SUN, control, and E-FLAX, respectively; pooled SEM $=0.2 ; P<0.05)$. The average number of CL per cow on d 16 of the estrous cycle tended to be higher in the E-FLAX group than in the control and E-SUN groups (1.3, 1.0, and 1.0 CL for EFLAX, control, and E-SUN, respectively; pooled SEM $=0.1 ; P<0.1)$. The $\mathrm{CL}$ diameter on $\mathrm{d} 16$ of the cycle tended to be larger in the E-SUN group than in the E-FLAX group, with no differences between the other groups $(28.4 \pm 1.7,26.0 \pm 2.3$, and $24.2 \pm 1.5 \mathrm{~mm}$ for E-SUN, control, and E-FLAX, respectively; $P<$ $0.08)$. No differences were observed between groups in $\mathrm{P}_{4}$ concentrations in plasma on $\mathrm{d} 16(5.6,6.6$, and 6.0 $\mathrm{ng} / \mathrm{mL}$ for control, E-FLAX, and E-SUN, respectively; pooled SEM $=0.8$ ).

A delay in visible estrus manifestation after $\mathrm{PGF}_{2 \alpha}$ injection was observed in the E-FLAX group as compared with the E-SUN group. On average, the interval from $\mathrm{PGF}_{2 \alpha}$ administration to observed estrus behavior was longer in the E-FLAX group than in the E-SUN group, but did not differ from that in the control group $(2.9,2.3$, and $2.6 \mathrm{~d}$ for E-FLAX, E-SUN, and control, respectively; pooled SEM $=0.2 ; P<0.04)$. In a test that determined the deviation in activity, the increase in activity was lower at $2 \mathrm{~d}$ after $\mathrm{PGF}_{2 \alpha}$ injection in the E-FLAX group than in the control and E-SUN groups $(2.0 \pm 38.8,116.2 \pm 45.9$, and $135.9 \pm 38.8 \%$ for E-FLAX, control, and E-SUN, respectively; $P<$ 0.05). Three days after $\mathrm{PGF}_{2 \alpha}$ injection, the activity in the E-FLAX group tended to be lower than that in the E-SUN group $(P<0.07)$, and at $4 \mathrm{~d}$ after $\mathrm{PGF}_{2 \alpha}$ injection, the activity in the E-FLAX group was lower than that in the E-SUN group $(P<0.05)$. On $\mathrm{d} 5$ after $\mathrm{PGF}_{2 \alpha}$ injection, the activity in the E-FLAX group was higher than that in the other groups $(P<0.05)$.

The $\mathrm{P}_{4}$ concentrations in plasma after $\mathrm{PGF}_{2 \alpha}$ injection are shown in Figure 2, which shows a delay in initiation of the luteal phase in the cows fed E-FLAX as compared with those in the other groups. The average $\mathrm{P}_{4}$ concentrations in plasma on d 9 post $\mathrm{PGF}_{2 \alpha}$ injection were lower in the cows fed E-FLAX than in those fed E-SUN $(P<0.01)$. The average $\mathrm{P}_{4}$ concentrations in plasma on $\mathrm{d} 11$ post $\mathrm{PGF}_{2 \alpha}$ injection were also lower in the E-FLAX group than in the E-SUN group $(P<$ $0.05)$ and tended $(P<0.07)$ to be lower than those in the control group $(0.57 \pm 0.41,2.43 \pm 0.38$, and $1.85 \pm 0.50 \mathrm{ng} / \mathrm{mL}$ for E-FLAX, E-SUN, and control, respectively).

\section{Aspiration of Large Follicles}

The first follicle aspiration was conducted $63 \pm 1$ d after of treatments commenced, with no differences 
Table 5. Least squares means of fatty acid profile in plasma ( $\%$ of total fatty acids)

\begin{tabular}{|c|c|c|c|c|c|}
\hline \multirow[b]{2}{*}{ Fatty acid } & \multicolumn{3}{|c|}{ Treatment $^{1}$} & \multirow[b]{2}{*}{$P$-value } & \multirow[b]{2}{*}{ SEM } \\
\hline & Control & E-FLAX & E-SUN & & \\
\hline C14:0 & 1.52 & 1.67 & 1.53 & NS & 0.10 \\
\hline C14:1 & $0.73^{\mathrm{b}}$ & $0.98^{\mathrm{a}}$ & $0.82^{\mathrm{ab}}$ & $*$ & 0.07 \\
\hline C16:0 & 12.56 & 12.23 & 11.73 & NS & 0.40 \\
\hline C16:1 & 1.33 & 1.24 & 1.08 & NS & 0.14 \\
\hline C18:0 & 11.56 & 13.52 & 13.32 & NS & 0.79 \\
\hline C18:1n-9 & $9.26^{\mathrm{a}}$ & $7.95^{\mathrm{b}}$ & $7.61^{\mathrm{b}}$ & $* * *$ & 0.23 \\
\hline C18:2n-6 & $53.72^{\mathrm{a}}$ & $48.98^{\mathrm{b}}$ & $55.48^{\mathrm{a}}$ & $* * *$ & 0.97 \\
\hline C18:2 cis & $2.62^{\mathrm{a}}$ & $2.06^{\mathrm{b}}$ & $2.11^{\mathrm{b}}$ & $*$ & 0.16 \\
\hline C18:3n-3 & $1.43^{\mathrm{b}}$ & $7.98^{\mathrm{a}}$ & $1.49^{\mathrm{b}}$ & $* * *$ & 0.22 \\
\hline C20:3n-6 & $2.60^{\mathrm{a}}$ & $1.60^{\mathrm{b}}$ & $2.27^{\mathrm{a}}$ & $* *$ & 0.16 \\
\hline $\mathrm{C} 20: 4 n-6$ & $2.64^{\mathrm{a}}$ & $1.79^{\mathrm{b}}$ & $2.54^{\mathrm{a}}$ & $* * *$ & 0.10 \\
\hline Saturated & 25.64 & 27.42 & 26.59 & NS & 1.05 \\
\hline MUFA $^{2}$ & $11.32^{\mathrm{a}}$ & $10.17^{\mathrm{b}}$ & $9.51^{\mathrm{b}}$ & $* * *$ & 0.27 \\
\hline $\mathrm{PUFA}^{3}$ & 63.01 & 62.41 & 63.90 & NS & 1.06 \\
\hline$n-3$ & $1.43^{\mathrm{b}}$ & $7.98^{\mathrm{a}}$ & $1.49^{\mathrm{b}}$ & $* * *$ & 0.22 \\
\hline$n-6$ & $58.96^{\mathrm{a}}$ & $52.37^{\mathrm{b}}$ & $60.30^{\mathrm{a}}$ & $* * *$ & 1.03 \\
\hline$n-6: n-3$ & $42.78^{\mathrm{a}}$ & $6.74^{\mathrm{b}}$ & $41.49^{\mathrm{a}}$ & $* * *$ & 1.84 \\
\hline
\end{tabular}

${ }^{\mathrm{a}, \mathrm{b}}$ Within rows, means with different superscript letters are statistically different.

${ }^{1}$ Treatments: cows were fed a lactating cow diet (control); a lactating cow diet that consisted of $1 \mathrm{~kg} / \mathrm{d}$ per cow (3.8\% of dietary DM) of encapsulated flaxseed, providing $242.2 \mathrm{~g}$ of C18:3n-3 (E-FLAX); or a lactating cow diet that consisted of $1 \mathrm{~kg} / \mathrm{d}$ per cow (3.8\% of dietary DM) of encapsulated sunflower, providing $260.0 \mathrm{~g}$ of C18:2n-6 (E-SUN).

${ }^{2}$ Monounsaturated fatty acids.

${ }^{3}$ Polyunsaturated fatty acids.

${ }^{*} P<0.05 ;{ }^{* *} P<0.01 ;{ }^{* * *} P<0.001$.

between groups in the average DIM at aspiration. Five cows that had a pattern of plasma $\mathrm{P}_{4}$ concentrations different from those expected $\left(\mathrm{P}_{4}<2 \mathrm{ng} / \mathrm{mL}\right.$ on the day of $\mathrm{PGF}_{2 \alpha}$ injection, or $\mathrm{P}_{4}>0.2 \mathrm{ng} / \mathrm{mL}$ on the day of aspiration) were excluded from the analysis. Twentyseven out of $47(57 \%)$ follicles larger than $7 \mathrm{~mm}$ that were aspirated were defined as $\mathrm{E}_{2}$-active and were subjected to further analysis.

The second follicle aspiration was conducted at $96 \pm 5 \mathrm{~d}$ in treatment. Four cows whose plasma $\mathrm{P}_{4}$ concentration patterns differed from those expected were excluded from the analysis. Nineteen out of 38 (50\%) follicles larger than $7 \mathrm{~mm}$ that were aspirated were defined as $\mathrm{E}_{2}$-active and were subjected to further analysis.

Because no treatment $x$ aspiration session interaction was detected, the results of the 2 aspirations were combined and are presented in Table 9. The average number of $\mathrm{E}_{2}$-active follicles per cow was higher in the E-FLAX group than in the other 2 groups (Table $9 ; P$ $<0.04)$. The $\mathrm{P}_{4}$ concentrations in FF were higher in the control group than in the E-FLAX group $(P<0.03)$, and $\mathrm{E}_{2}$ concentrations were lower in the E-FLAX group than in the E-SUN group $(P<0.05)$. No differences among groups in $\mathrm{A}_{4}$ concentrations or in contents of $\mathrm{P}_{4}$, $\mathrm{E}_{2}$, and $\mathrm{A}_{4}$ were observed. The $\mathrm{E}_{2}: \mathrm{P}_{4}$ ratio was higher in the E-SUN group than in the E-FLAX group $(P<$ $0.05)$.

\section{OPU}

Nineteen OPU sessions were conducted with control cows and cows fed E-FLAX, and 11 sessions were conducted with cows fed E-SUN. An in vitro fertilization (IVF) procedure was applied to the oocytes from 11 sessions with the control and E-FLAX groups and was applied to oocytes from 8 sessions with the E-SUN group. The oocytes from the remaining OPU sessions were used for analysis of the FA composition. The results of OPU and IVF sessions are shown in Table 10. The number of follicles that were observed and aspirated was higher in the cows fed E-FLAX than in control cows $(P<0.04)$. The number of oocytes collected per session tended to be lower in the E-SUN group than in the control group $(P<0.1)$, and the recovery rate tended to be higher in the control group than in the other groups $(P<0.08)$. The total numbers of grade 1,2 , and 3 oocytes collected by OPU were 408, 424, and 258 from the control, E-FLAX, and E-SUN group, respectively. The mean number of grade 1 oocytes per

Table 6. Least squares means of fatty acid profile in follicular fluid (\% of total fatty acids)

\begin{tabular}{lccccc}
\hline & \multicolumn{3}{c}{ Treatment $^{1}$} & & \\
\cline { 2 - 4 } Fatty acid & Control & E-FLAX & E-SUN & P-value & SEM \\
\hline C14:0 & 2.78 & 2.76 & 2.50 & NS & 0.17 \\
C14:1 & 1.27 & 1.26 & 1.12 & NS & 0.14 \\
C16:0 & 14.62 & 14.13 & 13.62 & NS & 0.65 \\
C16:1 & 1.71 & 1.41 & 1.32 & NS & 0.14 \\
C18:0 & 11.82 & 12.22 & 12.21 & NS & 0.44 \\
C18:1n-9 & $8.68^{\mathrm{a}}$ & $7.59^{\mathrm{b}}$ & $6.87^{\mathrm{c}}$ & $*$ & 0.34 \\
C18:2n-6 & $50.81^{\mathrm{b}}$ & $47.97^{\mathrm{c}}$ & $54.15^{\mathrm{a}}$ & $*$ & 1.06 \\
C18:2 cis & 2.49 & 2.64 & 2.89 & NS & 0.14 \\
C18:3n-3 & $1.40^{\mathrm{b}}$ & $7.25^{\mathrm{a}}$ & $1.40^{\mathrm{b}}$ & $* * *$ & 0.28 \\
C18:3n-6 & $0.23^{\mathrm{a}}$ & $0.04^{\mathrm{b}}$ & $0.17^{\mathrm{a}}$ & $*$ & 0.05 \\
C20:3n-6 & $2.05^{\mathrm{a}}$ & $1.26^{\mathrm{b}}$ & $1.92^{\mathrm{a}}$ & $* * *$ & 0.13 \\
C20:4n-6 & $2.15^{\mathrm{a}}$ & $1.46^{\mathrm{b}}$ & $2.02^{\mathrm{a}}$ & $* * *$ & 0.09 \\
Saturated & 29.22 & 29.11 & 28.33 & NS & 1.08 \\
MUFA ${ }^{2}$ & $11.66^{\mathrm{a}}$ & $10.26^{\mathrm{b}}$ & $9.12^{\mathrm{b}}$ & $*$ & 0.50 \\
PUFA & $59.12^{\mathrm{b}}$ & $60.63^{\mathrm{ab}}$ & $62.55^{\mathrm{a}}$ & $*$ & 1.21 \\
n-3 & $1.40^{\mathrm{b}}$ & $7.25^{\mathrm{a}}$ & $1.40^{\mathrm{b}}$ & $* * *$ & 0.28 \\
n-6 & $55.24^{\mathrm{b}}$ & $50.73^{\mathrm{c}}$ & $58.27^{\mathrm{a}}$ & $*$ & 1.13 \\
n-6:n-3 & $41.42^{\mathrm{a}}$ & $7.18^{\mathrm{b}}$ & $43.18^{\mathrm{a}}$ & $* * *$ & 2.12 \\
\hline
\end{tabular}

${ }^{a-c}$ Within rows, means with different superscript letters are statistically different.

${ }^{1}$ Treatments: cows were fed a lactating cow diet (control); a lactating cow diet that consisted of $1 \mathrm{~kg} / \mathrm{d}$ per cow (3.8\% of dietary DM) of encapsulated flaxseed, providing $242.2 \mathrm{~g}$ of C18:3n-3 (E-FLAX); or a lactating cow diet that consisted of $1 \mathrm{~kg} / \mathrm{d}$ per cow (3.8\% of dietary DM) of encapsulated sunflower, providing $260.0 \mathrm{~g}$ of C18:2n-6 (E-SUN).

${ }^{2}$ Monounsaturated fatty acids.

${ }^{3}$ Polyunsaturated fatty acids.

${ }^{*} P<0.05 ;{ }^{* * *} P<0.001$. 
Table 7. Least squares means of fatty acid profile in granulosa cells (\% of total fatty acids)

\begin{tabular}{|c|c|c|c|c|c|}
\hline \multirow[b]{2}{*}{ Fatty acid } & \multicolumn{3}{|c|}{ Treatment $^{1}$} & \multirow[b]{2}{*}{$P$-value } & \multirow[b]{2}{*}{ SEM } \\
\hline & Control & E-FLAX & E-SUN & & \\
\hline C14:0 & 5.30 & 5.97 & 6.63 & NS & 1.30 \\
\hline C14:1 & 1.31 & 0.85 & 0.71 & NS & 0.53 \\
\hline C16:0 & $36.14^{\mathrm{a}}$ & $28.11^{\mathrm{b}}$ & $33.45^{\mathrm{ab}}$ & $*$ & 2.33 \\
\hline C16:1 & $3.82^{\mathrm{ab}}$ & $3.39^{\mathrm{b}}$ & $5.41^{\mathrm{a}}$ & $*$ & 0.77 \\
\hline C18:0 & 20.85 & 17.20 & 18.64 & NS & 1.38 \\
\hline C18:1n-9 & 10.26 & 11.83 & 13.03 & NS & 2.17 \\
\hline C18:2n-6 & $20.71^{\mathrm{ab}}$ & $28.09^{\mathrm{a}}$ & $20.55^{\mathrm{b}}$ & $*$ & 2.97 \\
\hline $\mathrm{C} 18: 2$ cis & 0.25 & 0.29 & 0.00 & NS & 0.23 \\
\hline C18:3n-3 & $0.65^{\mathrm{b}}$ & $3.44^{\mathrm{a}}$ & $0.80^{\mathrm{b}}$ & $* * *$ & 0.45 \\
\hline C18:3n-6 & $0.00^{\mathrm{ab}}$ & $0.34^{\mathrm{a}}$ & $0.00^{\mathrm{b}}$ & $*$ & 0.14 \\
\hline $\mathrm{C} 20: 3 \mathrm{n}-6$ & 0.00 & 0.40 & 0.01 & NS & 0.19 \\
\hline C20:4n-6 & 0.70 & 0.74 & 0.76 & NS & 0.59 \\
\hline Saturated & 62.29 & 51.28 & 58.72 & NS & 3.96 \\
\hline MUFA $^{2}$ & 15.39 & 15.42 & 19.15 & NS & 2.18 \\
\hline PUFA $^{3}$ & $22.32^{\mathrm{b}}$ & $32.95^{\mathrm{a}}$ & $22.13^{\mathrm{b}}$ & $*$ & 3.39 \\
\hline$n-3$ & $0.65^{\mathrm{b}}$ & $3.44^{\mathrm{a}}$ & $0.80^{\mathrm{b}}$ & $* * *$ & 0.45 \\
\hline$n-6$ & $21.41^{\mathrm{ab}}$ & $29.57^{\mathrm{a}}$ & $21.33^{\mathrm{b}}$ & $*$ & 3.14 \\
\hline$n-6: n-3$ & $29.41^{\mathrm{a}}$ & $9.26^{\mathrm{b}}$ & $22.46^{\mathrm{a}}$ & $* *$ & 3.55 \\
\hline
\end{tabular}

${ }^{\mathrm{a}, \mathrm{b}}$ Within rows, means with different superscript letters are statistically different.

${ }^{1}$ Treatments: cows were fed a lactating cow diet (control); a lactating cow diet that consisted of $1 \mathrm{~kg} / \mathrm{d}$ per cow (3.8\% of dietary DM) of encapsulated flaxseed, providing $242.2 \mathrm{~g}$ of C18:3n-3 (E-FLAX); or a lactating cow diet that consisted of $1 \mathrm{~kg} / \mathrm{d}$ per cow (3.8\% of dietary DM) of encapsulated sunflower, providing $260.0 \mathrm{~g}$ of C18:2n-6 (E-SUN).

${ }^{2}$ Monounsaturated fatty acids.

${ }^{3}$ Polyunsaturated fatty acids.

${ }^{*} P<0.05 ;{ }^{* *} P<0.01$; *** $P<0.001$.

cow per session was lower in the E-SUN group than in the control group $(P<0.05)$, and the mean numbers of grade 1 and 2 oocytes tended to be lower in the E-SUN group than in the control group $(P<0.1)$. The mean number of oocytes per cow that was selected for IVF was higher in the E-FLAX group than in the E-SUN group $(P<0.04)$, and the number of oocytes selected in the E-SUN group tended to be lower than that in the control group $(P<0.1)$. The proportions of matured oocytes (approximately $86 \%$ ) did not differ between groups. The cleavage rate in the E-FLAX group was higher than that in the control group $(P<0.05)$, with no differences among the other groups.

\section{DISCUSSION}

In the present study, feeding dairy cows with encapsulated fat rich in C18:3n-3 (of flaxseed origin; low n-6:n-3 ratio) changed the composition of FA in milk, plasma, and ovarian compartments in a manner that increased the n-3 FA proportion and decreased the n6:n-3 ratio. Furthermore, dietary n-3 FA influenced the follicular status and the interval between the $\mathrm{PGF}_{2 \alpha}$ injection and initiation of the subsequent luteal phase. A higher cleavage rate of oocytes was observed in the cows fed E-FLAX as compared with control cows. The effects on ovarian function demonstrated in the present study might be related to the modification in FA composition.

\section{Milk and Milk Solids Yield}

In general, the differences in milk yield and composition between groups in the present study could be attributed to the small number of animals used ( 7 to 9 cows per treatment). The milk yield in the present study was unaffected by E-FLAX supplementation as compared with the milk yield of control cows, which is in agreement with other reports in which a variety of flaxseed sources were fed (Kennelly, 1996; Mustafa et al., 2003; Gonthier et al., 2005). In the current study, concentrations of milk fat were higher in the E-FLAX group than in the other groups, a result not observed in other reports (Petit et al., 2004; Gonthier et al. 2005). Moreover, in the study by Mustafa et al. (2003), lower milk fat concentrations were observed for cows fed micronized or untreated flaxseed. The lower de novo synthesis of FA in the mammary gland reported by Mustafa et al. (2003) was not found in the current study (Table 3), and we do not have a putative explanation for the higher fat percentage in the E-FLAX group. Other studies that used unprotected sunflower observed a reduction in fat concentration when feeding sunflower (Sarrazin et al., 2004; Rego et al., 2005), which is in contrast to our findings. The unprotected sunflower might have increased the formation of FA associated with milk fat depression, such as conjugated

Table 8. Fatty acid profile in cumulus oocytes complex (\% of total fatty acids)

\begin{tabular}{lccc}
\hline & \multicolumn{3}{c}{ Treatment $^{1}$} \\
\cline { 2 - 4 } Fatty acid & Control & E-FLAX & E-SUN \\
\hline C14:0 & 11.24 & 2.34 & 10.49 \\
C16:0 & 47.91 & 39.01 & 39.39 \\
C18:0 & 23.37 & 37.78 & 21.77 \\
C18:1n-9 & 6.01 & 7.92 & 12.87 \\
C18:2n-6 & 4.45 & 6.91 & 10.68 \\
C18:3n-3 & 0.00 & 4.73 & 0.00 \\
C20:4n-6 & 7.02 & 1.31 & 4.80 \\
Saturated & 82.52 & 79.13 & 71.65 \\
MUFA & 6.01 & 7.92 & 12.87 \\
PUFA & & 12.95 & 15.48 \\
n-3 & 11.47 & 4.73 & 0.00 \\
n-6 & 0.00 & 8.22 & 15.48 \\
n-6:n-3 & 11.47 & 1.74 & -
\end{tabular}

${ }^{1}$ Treatments: cows were fed a lactating cow diet (control); a lactating cow diet that consisted of $1 \mathrm{~kg} / \mathrm{d}$ per cow $(3.8 \%$ of dietary DM) of encapsulated flaxseed, providing $242.2 \mathrm{~g}$ of C18:3n-3 (E-FLAX); or a lactating cow diet that consisted of $1 \mathrm{~kg} / \mathrm{d}$ per cow (3.8\% of dietary DM) of encapsulated sunflower, providing $260.0 \mathrm{~g}$ of C18:2n-6 (E-SUN).

${ }^{2}$ Monounsaturated fatty acids.

${ }^{3}$ Polyunsaturated fatty acids. 
Table 9. Follicle concentrations and contents of progesterone, androstenedione, and estradiol of estradiol-active ( $\mathrm{E}_{2}$-active) follicles

\begin{tabular}{lcccr}
\hline & \multicolumn{3}{c}{ Treatment $^{1}$} \\
\cline { 2 - 4 } Item & Control & E-FLAX & E-SUN & SEM \\
\hline Cows, n & 6 & 7 & 9 & \\
Number of follicles & 11 & 16 & 18 & \\
Follicles per aspiration & $1.14^{\mathrm{b}}$ & $1.54^{\mathrm{a}}$ & $1.07^{\mathrm{b}}$ & 0.12 \\
Diameter, mm & 11.7 & 11.4 & 12.5 & 0.88 \\
Volume, mL & 1.14 & 1.15 & 1.37 & 0.30 \\
Progesterone, ng/mL & $104.6^{\mathrm{a}}$ & $67.7^{\mathrm{b}}$ & $85.7^{\mathrm{ab}}$ & 10.5 \\
Androstenedione, ng/mL & 94.6 & 119.3 & 161.5 & 39.0 \\
Estradiol, ng/mL & $1,207.2^{\mathrm{ab}}$ & $838.8^{\mathrm{b}}$ & $1,340.7^{\mathrm{a}}$ & 189.4 \\
Estradiol:progesterone & $11.8^{\mathrm{ab}}$ & $11.5^{\mathrm{b}}$ & $16.9^{\mathrm{a}}$ & 2.1 \\
Progesterone, ng & 174.3 & 118.8 & 164.9 & 57.7 \\
Androstenedione, ng & 164.1 & 260.9 & 342.0 & 129.7 \\
Estradiol, ng & $2,360.0$ & $2,215.7$ & $2,537.8$ & 928.0 \\
\hline
\end{tabular}

${ }^{\mathrm{a}, \mathrm{b}}$ Within rows, means with different superscript letters are statistically different, $P<0.05$.

${ }^{1}$ Treatments: cows were fed a lactating cow diet (control); a lactating cow diet that consisted of $1 \mathrm{~kg} / \mathrm{d}$ per cow (3.8\% of dietary DM) of encapsulated flaxseed, providing $242.2 \mathrm{~g}$ of C18:3n-3 (E-FLAX); or a lactating cow diet that consisted of $1 \mathrm{~kg} / \mathrm{d}$ per cow (3.8\% of dietary DM) of encapsulated sunflower, providing $260.0 \mathrm{~g}$ of C18:2n-6 (E-SUN).

linoleic acid (Sarrazin et al., 2004), in comparison with the encapsulated sunflower used in the present study. In addition, the lower protein concentrations in the EFLAX group that were found in our study have not been reported elsewhere (Mustafa et al., 2003; Petit et al., 2004; Gonthier et al., 2005).

\section{FA Composition of Milk}

Feeding cows E-SUN increased the proportion of n-6 FA in milk fat, for the most part by increasing the C18:2n-6 FA, which is similar to other reports (Petit et al., 2004; Rego et al., 2005). This may have resulted from the high C18:2n- 6 concentrations in the E-SUN supplement. As was expected, E-FLAX increased the proportions n-3 FA in milk fat, which is in accordance with the results of Mustafa et al. (2003), Petit et al. (2004), and Gonthier et al. (2005) for cows fed a variety of flaxseed sources. It should be noted that in our study, the proportion of C18:3n-3 (the main n-3 FA) in the control group was lower than the control levels reported by Petit et al. (2004) and Gonthier et al. (2005). This discrepancy could be attributed to the higher forage content in the rations used by Petit et al. (2004) and Gonthier et al. (2005), which can be rich in C18:3n-3 (Dewhurst and King, 1998).

Although EPA (C20:5n-3) and DPA (C22:5n-3) were not detected in the E-FLAX supplement, those FA were approximately 4-fold higher in the milk fat of cows fed E-FLAX than in the milk fat of cows in the other groups. These essential long-chain PUFA might be synthesized in the liver from shorter chain FA by the
Table 10. Average follicles and oocytes number, maturation, and cleavage rate of oocytes collected by ovum pickup (OPU)

\begin{tabular}{lcccc}
\hline & \multicolumn{3}{c}{ Treatment $^{1}$} \\
\cline { 2 - 4 } Item & Control & E-FLAX & E-SUN & SEM \\
\hline Cows, n & 5 & 5 & 5 & \\
OPU sessions & 19 & 19 & 11 & \\
IVF $^{2}$ sessions & 11 & 11 & 8 & \\
Follicles, n/cow $^{\text {Oocytes, n/cow }}$ & $11.25^{\mathrm{b}}$ & $13.54^{\mathrm{a}}$ & $12.07^{\mathrm{ab}}$ & 0.73 \\
Oocyte recovery, \% & 5.20 & 4.88 & 3.75 & 0.56 \\
Grade 1 oocytes, n & 44.3 & 34.9 & 34.7 & 0.3 \\
Grade 1 + 2 oocytes, n & $3.74^{\mathrm{a}}$ & $3.45^{\mathrm{ab}}$ & $2.50^{\mathrm{b}}$ & 0.42 \\
Oocytes, n/cow for IVF & 3.12 & 3.98 & 3.02 & 0.46 \\
Matured oocytes, \% & 85.1 & $3.29^{\mathrm{a}}$ & $2.16^{\mathrm{b}}$ & 0.34 \\
Cleaved, \% of oocytes & $41.49^{\mathrm{b}}$ & 85.8 & 87.7 & 0.2 \\
\hline
\end{tabular}

${ }^{\mathrm{a}, \mathrm{b}}$ Within rows, means with different superscript letters are statistically different, $P<0.05$.

${ }^{1}$ Treatments: cows were fed a lactating cow diet (control); a lactating cow diet that consisted of $1 \mathrm{~kg} / \mathrm{d}$ per cow (3.8\% of dietary DM) of encapsulated flaxseed, providing $242.2 \mathrm{~g}$ of C18:3n-3 (E-FLAX); or a lactating cow diet that consisted of $1 \mathrm{~kg} / \mathrm{d}$ per cow (3.8\% of dietary DM) of encapsulated sunflower, providing $260.0 \mathrm{~g}$ of C18:2n-6 (E-SUN).

${ }^{2} \mathrm{IVF}=$ in vitro fertilization.

desaturation and elongation enzyme systems (Wathes et al., 2007). The C18:3n-3 is converted to C18:4n-3 and then to $\mathrm{C} 20: 4 \mathrm{n}-3$, which is the precursor of EPA; DPA is derived from EPA (Abayasekara and Wathes, 1999). The increased proportion of EPA in response to C18:3n-3 (from the flaxseed source), which could be attributed to the desaturation and elongation process, was also demonstrated by Petit (2003). The increase in long-chain n-3 FA in response to E-FLAX supplementation was also observed in human serum (Weill et al., 2002). These results confirm the postulation that desaturation and elongation of $\mathrm{C} 18: 3 \mathrm{n}-3$ into longer chain n-3 FA occurs in dairy cow tissues, as in human ones, and they are transformed into milk fat. This finding is of special interest because the long-chain n-3 FA (in particular EPA and DHA) are associated with disease prevention and therapeutics (Deckelbaum et al., 2006).

Feeding cows $242.2 \mathrm{~g} / \mathrm{d}$ of C18:3n-3 in encapsulated form resulted in a 5.8-fold increase in n-3 FA in milk in the present study. A variety of flaxseed forms have been used to test the magnitude of transfer of C18:3n-3 into milk fat, and the results have been diverse. Petit et al. (2004) fed cows untreated whole flaxseed that contained approximately $534 \mathrm{~g} / \mathrm{d}$ of C18:3n-3 and found a 1.9-fold increase in n-3 FA in milk fat, whereas Ambrose et al. (2006) observed an almost tripled content of C18:3n-3 in the milk of cows fed approximately $2 \mathrm{~kg} / \mathrm{d}$ of rolled flaxseed that contained $147 \mathrm{~g}$ of that FA. The differences in apparent transfer efficiency can be attributed to the differences in flaxseed form between studies, and it seems that feeding fats in the encapsulated form, 


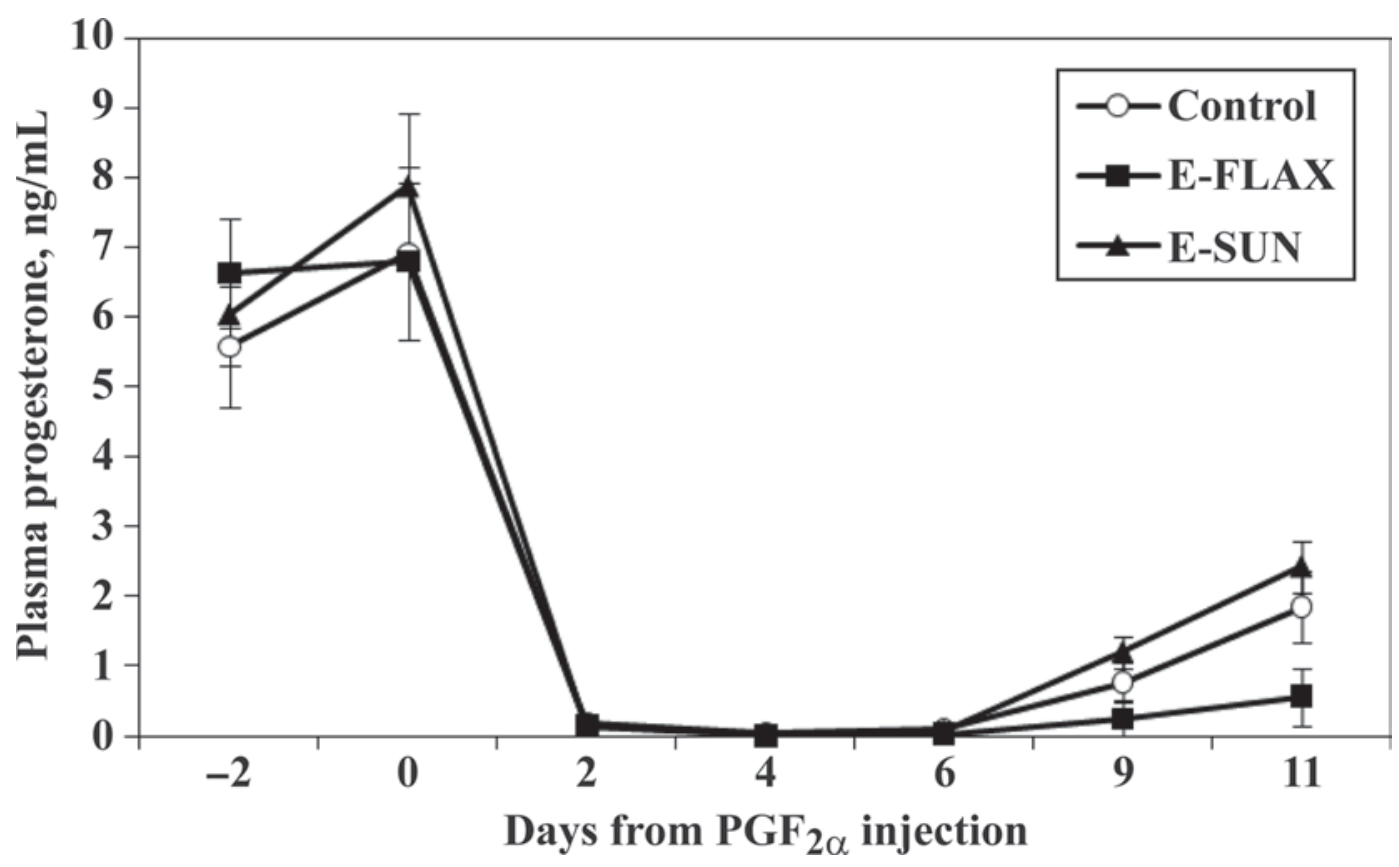

Figure 2. Average progesterone concentrations $(\mathrm{ng} / \mathrm{mL})$ in plasma relative to $\mathrm{PGF}_{2 \alpha}$ injection in cows fed a lactating cow diet $(\mathrm{O}$; control); a

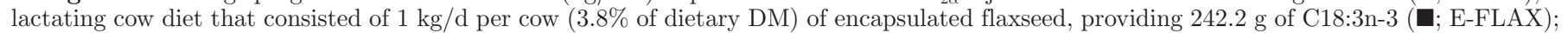
or a lactating cow diet that consisted of $1 \mathrm{~kg} / \mathrm{d}$ per cow $(3.8 \%$ of dietary DM) of encapsulated sunflower, providing $260.0 \mathrm{~g}$ of C18:2n-6 ( $\mathbf{\Delta}$ : E-SUN). The SEM for the whole period was $0.56 \mathrm{ng} / \mathrm{mL}$.

as in the current study, has resulted in relatively high transfer efficiency of PUFA into milk fat.

\section{FA Composition of Plasma}

The FA profile in plasma in the present study is similar to those reported by Petit et al. (2004) and Gonthier et al. (2005), in which C18:2n-6 was the predominant FA. However, our results confirm the report of Petit et al. (2004) in which the FA C18:2n-6 was within the range of 50 to $60 \%$ of plasma FA, and not 30 to $40 \%$ as reported by Gonthier et al. (2005). The plasma PUFA concentrations in our study were within the range of 60 to $70 \%$ and are consistent with the observations of Petit et al. (2004). The differences between groups in proportions of PUFA observed in milk fat were not detected in plasma, and this phenomenon was also found by Petit et al. (2004). It is an important finding of the current study that although the dietary treatment altered the relative proportions of plasma PUFA, the overall PUFA concentration in plasma remained constant (approximately 63\%).

Blood lipoproteins are the main source of long-chain FA that are incorporated into milk fat. In the current study, the n-3 FA in plasma were 5.6-fold higher in the E-FLAX group than in the control group, which was very similar in magnitude to that found in milk fat. Although the short- and medium-chain FA that are synthesized in the mammary gland constitute 30 to $35 \%$ of the FA in milk fat, the proportion of n-3 FA in milk fat remained similar to that in plasma. This indicated that the apparent transfer rate of n-3 FA from blood lipoproteins into milk fat was relatively high. Chilliard et al. (2000) concluded that the transfer efficiency of C18:3n-3 from the duodenum to milk is rather high (ranging from 35 to $70 \%$ ). In contrast to our findings, Petit et al. (2004) observed a lower magnitude of increase of n-3 FA in milk fat than in plasma (1.9- and 2.8 -fold, respectively). Two recently published papers thoroughly discuss the relationships among dietary lipid supply, duodenal flow, and mammary gland uptake of FA (Moate et al., 2007; Glasser et al., 2008). However, these papers focus on the rate of transfer from the duodenum into milk fat, rather than on mammary uptake of FA from plasma. Thompson and Christie (1991) and Moate et al. (2007) reported different mammary gland extraction and transfer efficiencies of FA from arterial triglycerides into the mammary gland. As the authors concluded (Moate et al., 2007; Glasser et al., 2008), more research is required to determine the relationship between supply of specific FA in the diet, duodenum flow, and plasma and milk fat FA profiles.

\section{FA Composition of FF}

The composition of FA in FF in the current study was similar to that observed in plasma. As in plasma, $\mathrm{C} 18: 2 \mathrm{n}-6$ was the predominant $\mathrm{FA}$ in $\mathrm{FF}$, with relatively 
high proportions of $\mathrm{C} 16: 0$ and $\mathrm{C} 18: 0$. The composition of FA in FF that was observed in this study is comparable with those observed by Castañeda-Gutiérrez et al. (2007) and Zachut et al. (2008).

In the present study, the proportion of $\mathrm{n}-3 \mathrm{FA}$ in $\mathrm{FF}$ obtained in vivo from $\mathrm{E}_{2}$-active follicles was 5.2-fold higher for cows fed E-FLAX, and the proportion of n-6 FA was higher in cows fed E-SUN. There is little information regarding the effects of dietary treatments on FA composition in FF; however, a few studies have addressed this topic. We demonstrated that dietary fat with a low ratio of unsaturated FA decreased the percentage of arachidonic acid (C20:4n-6) in the FF of $\mathrm{E}_{2}$-active follicles (Zachut et al., 2008). In a previous study, Zeron et al. (2002) observed an increase in proportions of C18:2n-6 and C22:6n-3 in FF phospholipids in response to fish oil supplementation in ewes. Castañeda-Gutiérrez et al. (2007) found an elevated proportion of $\mathrm{C} 18: 3 \mathrm{n}-3$ in the $\mathrm{FF}$ of $\mathrm{E}_{2}$-active follicles of cows fed encapsulated conjugated linoleic acid. In a recent study, Childs et al. (2008) observed higher proportions of EPA and DHA in FF obtained from follicles collected at an abattoir from heifers fed fish oil at 2.08 and $4.15 \%$ of the diet. Taken together, these results imply that dietary supplementation greatly influences the FA composition of FF.

\section{FA Composition of Granulosa Cells and COC}

Very few studies have determined the FA profile in granulosa cells and oocytes. Adamiak et al. (2006) examined the FA composition of granulosa cells obtained by the OPU procedure in dairy heifers and observed $55.7 \%$ SFA, which is similar to the results of the current study. However, the distribution between FA classes in granulosa cells (MUFA and PUFA) reported by Adamiak et al. (2006) was different from our findings. On average, the proportion of SFA in the COC in the current study was $79 \%$, which is similar to the proportions observed by Zeron et al. (1999) and Adamiak et al. (2006). In Matorras et al. (1998), the predominant FA in human COC were C16:0 and C18:0, which is in agreement with our findings in cow COC. McEvoy et al. (2000) and Kim et al. (2001) determined the FA profile of denuded oocytes from cattle and reported 54.5 and $57.1 \%$ SFA, 31.5 and $28.9 \%$ MUFA, and 11.1 and $14.1 \%$ PUFA, respectively. These results are inconsistent with the composition found in the current study and in that by Adamiak et al. (2006), and this discrepancy could be attributed to the effect of cumulus cells in these studies in comparison with denuded oocytes, which were determined in the studies by McEvoy et al. (2000) and Kim et al. (2001).
Although the composition of FA in plasma and FF was very similar, it was quite different from that found in granulosa cells and in COC. Whereas SFA constituted 25 to $30 \%$ of the total $\mathrm{FA}$ in plasma and $\mathrm{FF}$, it was increased to 50 to $60 \%$ in granulosa cells and to 70 to $80 \%$ in COC. In an opposite manner, the proportions of PUFA in plasma and FF were approximately $60 \%$, and these decreased to 20 to $30 \%$ in granulosa cells and to 10 to $15 \%$ in COC. In a similar manner, Reis et al. (2002) examined the FA profiles of ovine granulosa cells, oocytes, morula, and early blastocysts and observed differences in SFA, MUFA, and n-6 FA composition between granulosa cells and embryos at different developmental stages. As suggested by Adamiak et al. (2006), the changes in FA distribution classes between FF, granulosa cells, and $\mathrm{COC}$ indicate a selective uptake of specific classes of FA in ovarian compartments, which was also proposed by Zeron et al. (2002). Collectively, it could be concluded that FA composition of the ovarian compartments and embryos is quite different, and this may reflect the differences in tissue structure of various reproductive compartments associated with functional characteristics.

The impact of dietary FA supplementation on FA composition in the current study was demonstrated in FF, granulosa cells, and COC. To our knowledge, this is the first study that demonstrates incorporation of dietary n-3 FA into granulosa cells that were obtained in vivo. In one other study, the FA composition was altered in cumulus cells that were obtained from slaughtered ewes fed Ca salts of fish oil (Zeron et al., 2002). These findings indicate that although there is apparently a selective uptake mechanism in ovarian tissues, specific dietary supplementation could alter the FA profile in ovarian compartments. Incorporation of specific PUFA as n-3 FA into cell membranes might change the fluidity of membranes and the function of oocytes.

\section{Ovarian Follicular Status and Response to Estrous Cycle Synchronization}

In the present study, dietary C18:3n-3 (low n-6:n-3 ratio) fed to dairy cows increased the number of small follicles in the ovary, whereas dietary C18:2n-6 (high n-6:n-3 ratio) increased the number of large follicles as compared with control cows. The impact on ovarian follicle development of supplementing dairy cows with PUFA was investigated in several studies, and the results varied. Robinson et al. (2002) observed increased numbers of medium-sized (5- to 10-mm) follicles on d 5 and 15 of the estrous cycle in cows that received fat rich in C18:2n- 6 at $270 \mathrm{~g} / \mathrm{d}$ per cow, in comparison with control cows, but they did not record follicles smaller 
than $5 \mathrm{~mm}$. In contrast to the present findings, Ponter et al. (2006) reported an increased number of small follicles in cows fed extruded soybeans (rich in C18:2n-6) at $2 \mathrm{~kg} / \mathrm{d}$ per cow, compared with those fed extruded flaxseed (rich in C18:3n-3) at $2 \mathrm{~kg} / \mathrm{d}$ per cow, with no differences in the numbers of medium or large follicles. In another study Heravi Moussavi et al. (2007) observed higher numbers of medium-sized (5- to $10-\mathrm{mm}$ ) follicles in cows that were fed $5 \%$ fish meal than in control cows or those fed smaller proportions (1.25 and 2.5\%) of fish meal, which is not in accord with the present findings. However, Petit et al. (2004), who fed cows Ca salts of palm oil, whole flaxseed, whole sunflower seed (6.2 to $6.7 \%$ of DM), or no supplementary fat, found no differences among treatments in follicle dynamics. The inconsistencies among these results might be due to differences in the amounts of PUFA supplied, the duration of supplementation, or both.

In the present study, we observed a longer interval from $\mathrm{PGF}_{2 \alpha}$ injection to behavioral estrus and development of the subsequent early luteal phase in cows fed E-FLAX than in the other groups. Robinson et al. (2002) also observed lower concentrations of $\mathrm{P}_{4}$ in plasma at the early luteal phase in cows fed diets rich in $\mathrm{C} 18: 3 \mathrm{n}-3$ or $\mathrm{C} 18: 2 \mathrm{n}-6$. One proposed explanation for the possible delay in the development of the luteal phase is that PUFA may influence the CL regression process in response to $\mathrm{PGF}_{2 \alpha}$ injection. Indeed, Burke et al. (1997) found that $2 \mathrm{~d}$ after injection of $\mathrm{PGF}_{2 \alpha}$, the proportion of cows with plasma $\mathrm{P}_{4}$ concentration $>1 \mathrm{ng} / \mathrm{mL}$ was higher in cows fed menhaden fish meal (rich in n-3 PUFA) than in control cows, which suggests that fish meal altered the dynamics of CL regression. Another possible explanation for the delayed luteal phase is that ovulation may be postponed in cows fed PUFA. Robinson et al. (2002) found that the interval from the LH surge to ovulation was more variable in cows fed C18:2n-6, and they suggested that the delayed ovulation in cows fed PUFA could be attributed to alterations in prostaglandin-mediated changes in LHreleasing hormone release (Ojeda et al., 1979; Kim and Ramirez, 1986). However, in the present study, a similar pattern of decline in $\mathrm{P}_{4}$ concentrations after $\mathrm{PGF}_{2 \alpha}$ injection was observed in all groups, which indicates a similarity among groups in CL luteolysis. According to our findings, it is more likely to assume that the relative delay in estrus behavior and increased $\mathrm{P}_{4}$ concentrations in cows fed E-FLAX observed in our study may have resulted from a delay in development of the preovulatory follicle and in the timing of ovulation rather than in CL luteolysis, and that this finally led to delayed luteal development.

\section{Hormone Concentrations in $E_{2}$-Active Preovulatory Follicles}

The concentrations of $\mathrm{E}_{2}$ and the $\mathrm{E}_{2}: \mathrm{P}_{4}$ ratio in $\mathrm{E}_{2^{-}}$ active follicles were lower in cows fed E-FLAX than in those fed E-SUN. Thangavelu et al. (2007) reported numerically, but not significantly, lower $\mathrm{E}_{2}$ concentrations in the FF of dairy cows fed whole flaxseed than in those fed sunflower seed or saturated fat, which is consistent with the present results. However, Robinson et al. (2002) observed higher plasma $\mathrm{E}_{2}$ concentrations in cows fed C18:3n-3 than in those fed C18:2n-6, which is associated with higher steroidogenesis of $\mathrm{E}_{2}$ by the dominant follicle. The lower $\mathrm{E}_{2}$ concentrations in $\mathrm{FF}$ observed in the E-FLAX group can be attributed to the delay in preovulatory follicle development because the FF aspiration was conducted at a fixed time after $\mathrm{PGF}_{2 \alpha}$ injection. Thus, Robinson et al. (2002) determined peak plasma $\mathrm{E}_{2}$ concentrations, and it might be that in spite of the postulated delay in preovulatory follicle development, the rates of synthesis, but not peak levels of $\mathrm{E}_{2}$, were altered by dietary C18:3n-3.

The proportion of C20:4n-6 observed in FF was lower in cows fed E-FLAX than in the other groups. Steroid synthesis requires increased expression of StAR (steroidogenic acute regulatory protein), which mediates the transfer of cholesterol from the cytosol to the inner mitochondrial membrane (Stocco and Clark, 1996). Because the expression of StAR is upregulated by C20:4n-6 (Wang et al., 2000), the lower level of C20:4n-6 in the FF of cows fed E-FLAX may be associated with a decrease in the rate of $\mathrm{E}_{2}$ synthesis.

In the present study, a higher $\mathrm{E}_{2}: \mathrm{P}_{4}$ ratio was found in the $\mathrm{FF}$ of $\mathrm{E}_{2}$-active follicles in the E-SUN group than in the E-FLAX group, which is in agreement with our previous findings (Zachut et al., 2008). It is well established that the $\mathrm{E}_{2}: \mathrm{P}_{4}$ ratio is one of the most precise indicators of follicle health (Ireland and Roche 1982), and C18:2n-6 appears to have a positive effect on the characteristics of the preovulatory follicle.

\section{OPU and Oocyte Quality}

In the present study, we observed more follicles that were candidates for OPU in ovaries of the E-FLAX group than in follicles of the control group, which is consistent with the larger number of small follicles found in ovaries that were monitored during the estrous cycle. In a recent study, Ireland et al. (2008) observed a positive relationship between the number of antral follicles $>3 \mathrm{~mm}$ counted during the follicular wave and the morphologically healthy follicles and oocytes. Taken together, these findings support the hypothesis that 
C18:3n-3 could improve oocyte quality. Larger numbers of follicles in ovaries were also reported in ewes fed fish oil (Zeron et al., 2002), but not in cows fed flaxseed oil during the summer season (Bilby et al., 2006b). The average number of follicles found in the present study was approximately twice as great as the number reported by Bilby et al. (2006b), which could be attributed to the different seasons of oocyte collection (i.e., winter and summer, respectively). However, the average number of oocytes collected in the present study was similar to that found by Bilby et al. (2006b), which suggests differences between the recovery rates in the respective studies. A higher proportion of grade 1 oocytes was observed in ewes fed fish oil (Zeron et al., 2002), but this was not found in cows fed E-FLAX in the present study. Moreover, we found fewer grade 1 oocytes in the E-SUN group than in the control group, whereas Bilby et al. (2006b) reported no differences in oocyte grades between cows fed fats that supplied either $71 \mathrm{~g} / \mathrm{d}$ per cow of C18:2n-6 or $140 \mathrm{~g} / \mathrm{d}$ per cow of C18:3n-3. In the current study, higher cleavage rates were found in cows fed E-FLAX than in control cows, which was not observed by Bilby et al. (2006b) in cows fed flaxseed oil during the summer. The lack of response in the latter study, with lactating cows, was attributed to the uptake and utilization of FA by the mammary gland, which did not permit a change in follicular content of FA (Bilby et al., 2006b). Bilby et al. (2006b) also suggested that in the small follicles, which are the target of OPU, there may not have been sufficient FA to benefit the oocytes, cumulus cells, or FF. However, in the present study we demonstrated a considerable increase in the proportion of C18:3n-3 in ovarian compartments such as FF, granulosa cells, and COC, which could account for the response we obtained.

As mentioned, we observed increased numbers of follicles and a higher cleavage rate of oocytes in the cows fed E-FLAX than in control cows. Several studies have investigated the impact of specific FA on oocyte competence and development in vitro. Homa and Brown (1992), using ovaries collected in an abattoir, cultured bovine oocytes with C18:2n- 6 and noticed a reduction in the spontaneous breakdown of germinal vesicles compared with that in oocytes cultured without FA. In a study by Hochi et al. (1999), embryos cultured in $0.3 \%$ BSA with C18:2n-6 exhibited reduced development to the morula stage and further reduced development to the blastocyst stage compared with embryos cultured in $0.3 \%$ BSA without C18:2n-6. Recently, Cerri et al. (2009) observed a tendency for a higher fertilization rate and improved embryo quality in cows fed a mixture of Ca salts of C18:2n- 6 and C18:1-trans at $2 \%$ of $\mathrm{DM}$; the embryos of these cows also contained more blastomeres than those of cows fed palm oil. Neverthe- less, in the present study we did not observe beneficial effects of C18:2n-6 on oocyte competence, which is inconsistent with these reports. Dietary PUFA containing a high proportion of $\mathrm{C} 18: 3 \mathrm{n}-3$ were also reported to improve conception rates in dairy cows (Petit et al., 2001; Ambrose et al., 2006) and to decrease pregnancy losses (Ambrose et al., 2006; Petit and Twagiramungu, 2006). Conversely, SFA were shown to be detrimental to oocyte competence and development; Leroy et al. (2005) demonstrated that the SFA palmitic (C16:0) and stearic $(\mathrm{C} 18: 0)$ reduced the cleavage rate and the development rate of blastocysts in vitro compared with the effect of oleic acid (C18:1). In addition, Thangavelu et al. (2007) found fewer blastomeres in cows fed SFA than in those fed sunflower oil or flaxseed. Collectively, these studies indicate an effect of specific FA on oocyte competence, which may be due to changes in the surroundings of the oocytes or to incorporation of specific FA into the cell membrane and the intracellular environment. Although the effects of PUFA on the cellular and molecular pathways involved in the fertilization process in the cow are largely unknown, Santos et al. (2008) and Cerri et al. (2009) concluded that increased intake of PUFA might affect the FA composition of reproductive tissues and thereby improve the fertilization rate and embryonic development. Indeed, we demonstrated incorporation of n-3 FA into COC, a phenomenon that could be associated with the higher cleavage rate in the E-FLAX group. Although we demonstrated some beneficial effects of $\mathrm{C} 18: 3 \mathrm{n}-3$ on oocyte quality, more in vivo research is needed to elucidate this issue.

\section{CONCLUSIONS}

Supplementing dairy cows with E-FLAX altered the FA composition of milk fat, plasma, FF, granulosa cells, and COC in a manner that enhanced the proportion of n-3 FA and reduced the n-6:n-3 ratio. Similarly, but less prominently, supplementing cows with E-SUN increased the $\mathrm{n}-6 \mathrm{FA}$ in milk fat and $\mathrm{FF}$, but not in plasma and ovarian compartments. Differences were observed in the composition of FA classes between plasma and FF as compared with granulosa cells and oocytes, which may indicate selective uptake of $\mathrm{FA}$ in ovarian compartments. Dietary E-FLAX (low n-6:n-3 ratio) increased the number of small follicles and the number of follicles collected by OPU, and also enhanced the cleavage rate of IVF oocytes compared with the control group. A delayed response to the $\mathrm{PGF}_{2 \alpha}$ injection was observed in cows fed E-FLAX, which was reflected in delays in the manifestation of behavioral estrus and in the development of the subsequent early luteal phase. These findings could be related to a modification in the FA composition of plasma and ovarian compartments 
in response to dietary supplementation. However, the mechanism by which dietary n-3 FA affects physiological and functional aspects of the ovary is not clear and should be elucidated in further research.

\section{ACKNOWLEDGMENTS}

The authors gratefully acknowledge the kind donation of the encapsulated fats by SILA (Venice, Italy). We also thank the team at the experimental dairy farm at the Volcani Center (Bet Dagan, Israel) for their assistance with animal care.

\section{REFERENCES}

Abayasekara, D. R., and D. C. Wathes. 1999. Effects of altering dietary fatty acid composition on prostaglandin synthesis and fertility. Prostaglandins Leukot. Essent. Fatty Acids 61:275-287.

Adamiak, S. J., K. Powell, J. A. Rooke, R. Webb, and K. D. Sinclair. 2006. Body composition, dietary carbohydrates and fatty acids determine post-fertilisation development of bovine oocytes in vitro. Reproduction 131:247-258.

Ambrose, D. J., J. P. Kastelic, R. Corbett, P. A. Pitney, H. V. Petit, J. A. Small, and P. Zalkovic. 2006. Lower pregnancy losses in lactating dairy cows fed a diet enriched in $\alpha$-linolenic acid. J. Dairy Sci. 89:3066-3074.

AOAC. 1995. Official Methods of Analysis. Vol. 2. Assoc. Off. Anal. Chem., Arlington, VA.

Bilby, T. R., J. Block, B. C. do Amaral, O. Sa Filho, F. T. Silvestre, P. J. Hansen, C. R. Staples, and W. W. Thatcher. 2006b. Effects of dietary unsaturated fatty acids on oocyte quality and follicular development in lactating dairy cows in summer. J. Dairy Sci. 89:3891-3903.

Bilby, T. R., T. Jenkins, C. R. Staples, and W. W. Thatcher. 2006a. Pregnancy, bovine somatotropin, and dietary n-3 fatty acids in lactating dairy cows: III. Fatty acid distribution. J. Dairy Sci. 89:3386-3399.

Burke, J. M., C. R. Staples, C. A. Risco, R. L. De La Sota, and W. W. Thatcher. 1997. Effect of ruminant grade menhaden fish meal on reproductive and productive performance of lactating dairy cows. J. Dairy Sci. 80:3386-3398.

Castañeda-Gutiérrez, E., B. C. Benefield, M. J. de Veth, N. R. Santos, R. O. Gilbert, W. R. Butler, and D. E. Bauman. 2007. Evaluation of the mechanism of action of conjugated linoleic acid isomers on reproduction in dairy cows. J. Dairy Sci. 90:4253-4264.

Cerri, R. L. A., S. O. Juchem, R. C. Chebel, H. M. Rutigliano, R. G. S. Bruno, K. N. Galvão, W. W. Thatcher, and J. E. P. Santos. 2009. Effect of fat source differing in fatty acid profile on metabolic parameters, fertilization, and embryo quality in high-producing dairy cows. J. Dairy Sci. 92:1520-1531.

Childs, S., A. A. Hennessy, J. M. Sreenan, D. C. Wathes, Z. Cheng, C. Stanton, M. G. Diskin, and D. A. Kenny. 2008. Effect of level of dietary n-3 polyunsaturated fatty acid supplementation on systemic and tissue fatty acid concentrations and on selected reproductive variables in cattle. Theriogenology 70:595-611.

Chilliard, Y., A. Ferlay, R. J. Mansbridge, and M. Doreau. 2000. Ruminant milk fat plasticity: Nutritional control of saturated, polyunsaturated, trans and conjugated fatty acids. Ann. Zootech. 49:181-205.

Clandinin, M. T., S. Cheema, C. J. Field, M. L. Garg, J. Venkatraman, and T. R. Clandinin. 1991. Dietary fat: Exogenous determination of membrane structure and cell function. FASEB J. 13:27612769.

de Loos, F., C. van Vliet, P. van Maurik, and T. A. Kruip. 1989. Morphology of immature bovine oocytes. Gamete Res. 24:197204 .
Deckelbaum, R. J., T. S. Worgall, and T. Seo. 2006. n-3 fatty acids and gene expression. Am. J. Clin. Nutr. 83(Suppl.):1520S-1525S.

Dewhurst, R. J., and P. J. King. 1998. Effects of extended wilting, shading and chemical additives on the fatty acids in laboratory grass silages. Grass Forage Sci. 53:219-224.

Glasser, F., A. Ferlay, M. Doreau, P. Schmidely, D. Sauvant, and Y. Chilliard. 2008. Long-chain fatty acid metabolism in dairy cows: A meta-analysis of milk fatty acid yield in relation to duodenal flows and de novo synthesis. J. Dairy Sci. 91:2771-2785.

Gonthier, C., A. F. Mustafa, D. R. Ouellet, P. Y. Chouinard, R. Berthiaume, and H. V. Petit. 2005. Feeding micronized and extruded flaxseed to dairy cows: Effects on blood parameters and milk fatty acid composition. J. Dairy Sci. 88:748-756.

Heravi Moussavi, A. R., R. O. Gilbert, T. R. Overton, D. E. Bauman, and W. R. Butler. 2007. Effects of feeding fish meal and n-3 fatty acids on ovarian and uterine responses in early lactating dairy cows. J. Dairy Sci. 90:145-154.

Hochi, S., K. Kimura, and A. Hanada. 1999. Effect of linoleic acidalbumin in the culture medium on freezing sensitivity of in vitroproduced bovine morulae. Theriogenology 52:497-504.

Homa, S. T., and C. A. Brown. 1992. Changes in linoleic acid during follicular development and inhibition of spontaneous breakdown of germinal vesicles in cumulus-free bovine oocytes. J. Reprod. Fertil. 94:153-160.

International Dairy Federation. 2000. IDF standard 141c:2000: Determination of milk fat, protein and lactose content guidance on the operation of mid-infrared instruments. International Dairy Federation, Brussels, Belgium.

Ireland, J. J., and F. Roche. 1982. Development of antral follicles in cattle after prostaglandin-induced luteolysis: Changes in serum hormones, steroids in follicles fluids and gonadotropin receptors. Endocrinology 111:2077-2086.

Ireland, J. L., D. Scheetz, F. Jimenez-Krassel, A. P. Themmen, F. Ward, P. Lonergan, G. W. Smith, G. I. Perez, A. C. Evans, and J. J. Ireland. 2008. Antral follicle count reliably predicts number of morphologically healthy oocytes and follicles in ovaries of young adult cattle. Biol. Reprod. 79:1219-1225.

Kennelly, J. J. 1996. The fatty acid composition of milk fat as influenced by feeding oilseeds. Anim. Feed Sci. Technol. 60:137-152.

Kim, J. Y., M. Kinoshita, M. Ohnishi, and Y. Fukui. 2001. Lipid and fatty acid analysis of fresh and frozen-thawed immature and in vitro matured bovine oocytes. Reproduction 122:131-138.

Kim, K., and V. D. Ramirez. 1986. Effects of prostaglandin E2, forskolin and cholera toxin on cAMP production and in vitro LH$\mathrm{RH}$ release from the rat hypothalamus. Brain Res. 386:258-265.

Leroy, J. L., T. Vanholder, B. Mateusen, A. Christophe, G. Opsomer, A. de Kruif, G. Genicot, and A. Van Soom. 2005. Non-esterified fatty acids in follicular fluid of dairy cows and their effect on developmental capacity of bovine oocytes in vitro. Reproduction 130:485-495.

Matorras, R., J. I. Ruis, R. Mendoza, N. Ruiz, P. Sanjurjo, and F. J. Rodriguez-Escudero. 1998. Fatty acid composition of fertilizationfailed human oocytes. Hum. Reprod. 13:2227-2230.

Mattos, R., C. R. Staples, A. Arteche, M. C. Wiltbank, F. J. Diaz, T. C. Jenkins, and W. W. Thatcher. 2004. The effects of feeding fish oil on uterine secretion of $\mathrm{PGF}_{2 \alpha}$, milk composition, and metabolic status of periparturient Holstein cows. J. Dairy Sci. 87:921-932.

Mattos, R., C. R. Staples, and W. W. Thatcher. 2000. Effects of dietary fatty acids on reproduction in ruminants. Rev. Reprod. 5:38-45.

McEvoy, T. G., G. D. Coull, P. J. Broadbent, J. S. Hutchinson, and B. K. Speake. 2000. Fatty acid composition of lipids in immature cattle, pig and sheep oocytes with intact zona pellucida. J. Reprod. Fertil. 118:163-170.

Moallem, U., Y. Folman, A. Bor, A. Arav, and D. Sklan. 1999. Effect of calcium soaps of fatty acids and administration of somatotropin on milk production, preovulatory follicular development, and plasma and follicular fluid lipid composition in high yielding dairy cows. J. Dairy Sci. 82:2358-2368.

Moallem, U., M. Katz, H. Lehrer, L. Livshitz, and S. Yakoby. 2007. Role of peripartum dietary propylene glycol or protected fats on 
metabolism and early postpartum ovarian follicles. J. Dairy Sci. 90:1243-1254.

Moate, P. J., W. Chalupa, R. C. Boston, and I. J. Lean. 2007. Milk fatty acids. Variation in the concentration of individual fatty acids in bovine milk. J. Dairy Sci. 90:4730-4739.

Mustafa, A. F., P. Y. Chouinard, and D. A. Christensen. 2003. Effects of feeding micronised flaxseed on yield and composition of milk from Holstein cows. J. Sci. Food Agric. 83:920-926.

NRC. 2001. Nutrient Requirements of Dairy Cattle. 7th rev. ed. Natl. Acad. Sci., Washington, DC.

Ojeda, S. R., A. Negro-Vilar, and S. M. McCann. 1979. Release of prostaglandin $\mathrm{E}_{2}$ by hypothalamic tissue: Evidence of their involvement in catecholamine-induced LH-releasing-hormone release. Endocrinology 104:617-624.

Petit, H. V. 2003. Digestion, milk production, milk composition, and blood composition of dairy cows fed formaldehyde treated flaxseed or sunflower seed. J. Dairy Sci. 86:2637-2646.

Petit, H. V., R. J. Dewhurst, J. G. Proulx, M. Khalid, W. Haresign, and H. Twagiramungu. 2001. Milk production, milk composition, and reproductive function of dairy cows fed different fats. Can. J. Anim. Sci. 81:263-271.

Petit, H. V., C. Germiquet, and D. Lebel. 2004. Effect of feeding whole, unprocessed sunflower seeds and flaxseed on milk production, milk composition, and prostaglandin secretion in dairy cows. J. Dairy Sci. $87: 3889-3898$

Petit, H. V., and H. Twagiramungu. 2006. Conception rate and reproductive function of dairy cows fed different fat sources. Theriogenology 66:1316-1324.

Ponter, A. A., A. E. Parsy, M. Saade, J. P. Mialot, C. Ficheux, C Duvaux-Ponter, and B. Grimard. 2006. Effect of a supplement rich in linolenic acid added to the diet of postpartum dairy cows on ovarian follicle growth, and plasma fatty acid compositions. Reprod. Nutr. Dev. 46:19-29.

Prescott, S. L., and P. C. Calder. 2004. N-3 polyunsaturated fatty acids and allergic disease. Curr. Opin. Clin. Nutr. Metab. Care $7: 123-129$.

Rego, O. A., H. J. D. Rosa, P. V. Portugal, T. Franco, C. M. Vouzela, A. E. S. Borba, and R. J. B. Bessa. 2005. The effects of supplementation with sunflower and soybean oils on the fatty acid profile of milk fat from grazing dairy cows. Anim. Res. 54:1724.

Reis, A., L. M. Mitchell, J. A. Rooke, M. Ewen, M. A. Lomax, J. J. Robinson, and T. G. McEvoy. 2002. Fatty acid profiles during development of sheep eggs in vivo. Theriogenology 57:507. (Abstr.)

Robinson, R. S., P. G. Pushpakumara, Z. Cheng, A. R. Peters, D. R. Abayasekara, and D. C. Wathes. 2002. Effects of dietary polyunsaturated fatty acids on ovarian and uterine function in lactating dairy cows. Reproduction 124:119-131.

Roth, Z., A. Arav, A. Bor, Y. Zeron, R. Braw-Tal, and D. Wolfenson. 2001. Improvement of quality of oocytes collected in the autumn by enhanced removal of impaired follicles from previously heatstressed cows . Reproduction 122:737-744.

Santos, J. E. P., T. R. Bilby, W. W. Thatcher, C. R. Staples, and F. T. Silvestre. 2008. Long chain fatty acids of diet as factors influencing reproduction in cattle. Reprod. Domest. Anim. 43(Suppl. 2):2330 .

Sarrazin, P., A. F. Mustafa, P. Y. Chouinard, G. Raghavan, and S. Sotocinal. 2004. Performance of dairy cows fed roasted sunflower seed. J. Sci. Food Agric. 84:1179-1185.

SAS Institute. 2000. SAS User's Guide: Statistics. Version 8.1 edition. SAS Inst. Inc., Cary, NC.

Staples, C. R., J. M. Burke, and W. W. Thatcher. 1998. Influence of supplemental fats on reproductive tissues and performance of lactating cows. J. Dairy Sci. 81:856-871.

Stocco, D. M., and B. J. Clark. 1996. Role of steroidogenic acute regulatory protein $(\mathrm{StAR})$ in steroidogenesis. Biochem. Pharmacol. 51:197-205.

Thangavelu, G., M. G. Colazo, D. J. Ambrose, M. Oba, E. K. Okine, and M. K. Dyck. 2007. Diets enriched in unsaturated fatty acids enhance early embryonic development in lactating Holstein cows. Theriogenology 68:949-957.

Thompson, G. E., and W. W. Christie. 1991. Extraction of plasma triacylglycerols by the mammary gland of the lactating cow. J. Dairy Res. 58:251-255.

Wang, X. L. P. Walsh, A. D. Reinhart, and D. M. Stocco. 2000. The role of arachidonic acid in steroidogenesis and steroidogenic acute regulatory (StAR) gene and protein expression. J. Biol. Chem. 275:20204-20209.

Wathes, D. C., D. R. E. Abayasekara, and R. J. Aitken. 2007. Polyunsaturated fatty acids in male and female reproduction. Biol. Reprod. 77:190-201.

Weill, P., B. Schmitt, G. Chesneau, N. Daniel, F. Safraou, and P. Legrand. 2002. Effects of introducing linseed in livestock diet on blood fatty acid composition of consumers of animal products. Ann. Nutr. Metab. 46:182-191.

Zachut, M., A. Arieli, H. Lehrer, N. Argov, and U. Moallem. 2008. Dietary unsaturated fatty acids influence preovulatory follicle characteristics in dairy cows. Reproduction 135:683-692.

Zeron, Y., A. Arav, and D. Sklan. 1999. Fatty acid composition in bovine immature oocytes. Theriogenology 51:311. (Abstr.)

Zeron, Y., D. Sklan, and A. Arav. 2002. Effect of polyunsaturated fatty acid supplementation on biophysical parameters and chilling sensitivity of ewe oocytes. Mol. Reprod. Dev. 61:271-278. 